\title{
Meshfree and particle methods in biomechanics: Prospects and challenges
}

\section{Abstract}

The use of meshfree and particle methods in the field of bioengineering and biomechanics has significantly increased. This may be attributed to their unique abilities to overcome most of the inherent limitations of mesh-based methods in dealing with problems involving large deformation and complex geometry that are common in bioengineering and computational biomechanics in particular. This review article is intended to identify, highlight and summarize research works on topics that are of substantial interest in the field of computational biomechanics in which meshfree or particle methods have been employed for analysis, simulation or/and modeling of biological systems such as soft matters, cells, biological soft and hard tissues and organs. We also anticipate that this review will serve as a useful resource and guide to researchers who intend to extend their work into these research areas. This review article includes 333 references.

\section{Highlights}

- We present an up to date review of meshfree and particle methods, including their advantages and limitations.

- We comprehensively discuss past and recent applications of meshfree and particle methods in bioengineering and biomechanics.

- We identify research areas, directions, and opportunities for the application of meshfree and particle methods in bioengineering and biomechanics.

\section{Contents}
Abstract
1 Introduction
2 Overview of Meshfree and Particle Methods
3 Applications
4 Concluding Remarks and Prospects 
Acknowledgments

References

\section{Introduction}

According to Kojić et al. [1], bioengineering is defined as a broad field of scientific, biological, medical and engineering disciplines in which living systems, processes and materials are investigated together with non-living subjects, environments, and materials, in order to advance fundamental knowledge and improve lives. Advances in the field of bioengineering over the years have meaningfully transformed medical and health care, leading to an improved quality of life for human beings. These advances include X-ray, electrocardiogram, heart valve replacement, artificial kidneys, hips and knees, image-guided surgery, computer aided tomography (CT), magnetic resonance imaging (MRI), genomic sequencing and microarrays, laser surgery, ultrasound, and so on. It can be seen from this list that the scope of bioengineering is indeed very broad. This scope includes many areas of specialty, such as biomechanics, biomaterials, bioinstrumentation, bioimaging, bioinformatics, and so on.

As the title of this paper suggests, our focus lies within the field of biomechanics, which is an integral (not to mention the foremost) subset of bioengineering, involving the study of the structure and function of biological systems such as humans, animals, plants, organs, and cells by means of mechanics or mechanical methods. Therefore, we conclude that biomechanics is closely related to engineering since it essentially adopts basic and advanced engineering principles and methods, including applied mechanics, continuum mechanics, structural analysis, kinematics and dynamics, to analyze biological systems, while simultaneously bearing in mind that biological systems are much more complex than manbuilt systems.

Past, current and potential applications of mechanical concepts to real life problems are evident in the form of soft matter mechanics, kinesiology, human and animal movement, cell mechanics, tissue engineering, cancer biomechanics, bone remodeling, musculoskeletal and orthopedic biomechanics, cardiovascular biomechanics, ergonomics, occupational biomechanics, sports biomechanics and rehabilitation, allometry, and the so-called injury biomechanics. Over the past three decades, the use of numerical methods in bioengineering has gained significant attention compared to experimental techniques. These methods have 
proven to be the most economical choice and offer the possibility of investigating locations not accessible to experimental devices.

Many problems in the field of biomechanics may be solved computationally using meshbased methods such as the finite element method (FEM). However, finite element (FE) techniques, much like many other mesh-based methods, suffer from certain drawbacks in the modeling and simulation of biological systems such as soft tissue and cell deformation, minimally invasive surgical simulation as well as modeling of microvascular blood flow.

Some of the well-documented limitations of mesh-based methods are summarily itemized as follows. Firstly, all contact between tool and tissue must correspond to nodal points; hence, to prevent loss of accuracy, the density of the nodal points must be relatively high. This requires the application of extensive computational resources, in turn leading to high computational cost. Secondly, mesh distortion and entanglement during the large deformation of soft materials such as muscles, internal organs, skin, and cells results in reduced accuracy. Although remeshing algorithm may be employed to overcome this limitation, it often leads to increased computational cost and effort.

Furthermore, in situations where local stresses/strains are extremely large or during an explicit simulation of fluid flow, such as is found with hemodynamics, the swallow process, and cardiovascular activities, the creation of excellent quality meshes for use within the problem domain is a prerequisite with FEM, which ultimately leads to a loss of manpower time etc. Lastly, it is extremely difficult to represent complex geometry with unstructured mesh, which is necessary for the prediction of the complex remodeling process of biological tissues and the rupture of such biomaterial. In addition, the accuracy and smoothness of the stress fields obtained with meshless methods are very useful and convenient. Since most problems in computational biomechanics involve highly complex irregular geometries, large strains and deformation, the need for meshfree and particle methods, which circumvents most of the aforementioned limitations of mesh-based methods, cannot be overemphasized.

\section{Overview of Meshfree and Particle Methods}

As new phenomena and problems continue to emerge in the world of science and engineering, the need for more reliable and accurate computational techniques cannot be overstated. For some biomechanical problems, the limitations of conventional mesh-based computational techniques, such as finite difference method (FDM), finite element method 
(FEM) and finite volume method (FVM), become more obvious. For instance, finite elements based on a Lagrangian description of the kinematics are usually problematic. The results obtained are generally less accurate and lose their physical meaning due to the severe distortion of the FE meshes. This (alongside many other reasons) has motivated researchers to explore and develop new computational techniques, especially the so-called meshfree (or meshless) method.

The most distinctive feature of meshfree methods is that they do not use predefined meshes, at least for field variable interpolation, while the major difference between meshfree methods and conventional numerical methods is the manner in which the shape function is formulated. However, once the shape function has been obtained, meshfree methods, boundary element method (BEM) and FEM all use the same technique both to form the system equations and to acquire a solution to the problem under consideration. Generally, a meshfree method involves an algorithm that satisfies both of the following statements: (a) definition of the shape functions depends only on the node positions, and (b) evaluation of the nodal connectivity is bounded in time and depends exclusively on the total number of nodes in the domain.

The earliest documented form of the meshfree method, known as smoothed particle hydrodynamics (SPH), was first used in astronomical research [2]. Monaghan [3, 4] gave the method a more precise definition by explaining it as a kernel estimate, which revealed the inherent characteristic of the meshfree method to be its kernel node basis. In addition to astrophysics, the method also found use in fields such as civil and mechanical engineering, materials science, impact, penetration, and large deformation in solid mechanics, as well as many other engineering disciplines $[5,6]$.

Soon after, in 1992, a diffuse element method (DEM) was introduced by Nayroles et al. [7]. This method uses the moving least squares (MLS) approximation and its solution procedure is associated only with boundary information and node displacements; hence, the use of mesh and elements connectivity is no longer required. The MLS approximation was first used by Lancaster and Salkauskas [8] in curve-fitting applications. If the polynomial basis used in MLS approximation consists of only a constant, the method reduces to a weighted averaging technique, but if the weight functions are singular at the nodes with which they are prescribed, the MLS approximation becomes an interpolation, which implies that the approximation passes through the nodal data. 
Belytschko and his co-workers [9] made some modifications to the diffuse element method in order to obtain better accuracy. These modifications are as follows: the derivatives of the shape functions were evaluated exactly, Lagrange multipliers were introduced to the potential energy functional to enforce the essential boundary conditions, and the integration procedure was improved by using a regular cell structure, independent of the nodes. The resulting method was named the element-free Galerkin (EFG) method.

Over the years, the EFG has been used widely in continuum mechanics for various class of problems since it has proven to be a powerful numerical method. Instead of using domain meshing, as in the finite element method, EFG uses uniform or scattered node distribution in the problem domain. Numerical integrations are popularly performed using the Gauss quadrature method, which requires the use of background cells, and hence makes the method not 'truly' meshfree. While the method of SPH finds application in fluid mechanics, the methods of DEM and EFG are more oriented to solid mechanics. Compared to SPH, these methods offer good accuracy and stability, but are complex and 'more' computationally expensive.

As only node information is needed, EFG has many distinct advantages when compared with the traditional finite element method in solving various engineering mechanics problems, such as the structural and fracture mechanics, the behavior of materials, multiphase coupling, large deformation, and so on. Due to its superior properties, the EFG method has been widely used in many static and dynamic fracture mechanics problems [10-12], the modeling of material discontinuity [13], and with thin plates and shells [14, 15].

A subtle disadvantage of the EFG method is that the final algebraic equation system is sometimes ill-conditioned due to the MLS approximation used for the shape function construction [16]. As it is difficult to determine which of the algebraic equations is illconditioned, a good solution or even a correct numerical solution may be impossible to obtain. In addition, the need to find the inverse of the moment matrix leads to an increase in computation time. To overcome these problems, the improved moving least squares (IMLS) approximation has been developed to obtain the approximation function. Here, an orthogonal function system with a weight function is used as the basis function [17-19]. With the IMLS approximation, the algebraic equation system is not ill-conditioned and the inverse of the moment matrix can be obtained without an increase in computational cost due to the sparseness of the matrix. 
As there are fewer coefficients in the IMLS approximation than in the MLS approximation, fewer nodes may be employed to discretize the entire domain in the improved element-free Galerkin (EFG) method than with the conventional EFG method, which normally results in higher computation speed. Furthermore, the IEFG method has greater computational precision than the EFG method when the same numbers of nodes are distributed on the domain. Its accuracy and convergence have been tested for various categories of problems ranging from the biological population [20], where the degenerate parabolic equations arising from the spatial diffusion of biological populations are solved, 2D and 3D potential problems [18, 19], 2D fracture problems [17], and elastodynamics problems [21].

In 1998, Atluri and Zhu proposed two new meshfree methods based on the MLS approximation: the local Petrov-Galerkin (MLPG) method [22] and the local boundary integral equation (LBIE) method [23]. The advantage of these methods was the simplification of the integration process. Recently, Mirzaei and his co-workers proposed a new low-cost meshfree method, known as direct meshless local Petrov-Galerkin (DMLPG), which ignores the role of trial space and constructs the final stiffness matrix through direct approximations for local weak forms and boundary conditions [24, 25]. Liew et al. [26, 27] integrated the superiority of differential quadrature techniques and the MLS approximation to form the moving least-squares differential quadrature (MLSDQ) method.

Another successful and well-used meshfree method is the reproducing kernel particle method (RKPM) [28]. The RKPM improves the SPH method by introducing a correction function into the kernel function to satisfy the reproducing conditions. This modification allows the kernel or the weighting function to reproduce polynomials exactly to a specific order, thereby fulfilling the requirement of consistency conditions. The RKPM was proven to be equal to the MLS approximation when the correct function is the linear basis function [29]. Chen et al. [30] proposed a stabilized conforming nodal integration for Galerkin meshfree methods since integration by Gauss quadrature and direct nodal integration adds considerable complexity to solution procedures and leads to numerical instability due to the under-integration and vanishing derivatives of shape functions at the nodes, respectively.

Chen and his colleagues subsequently extended the use of RKPM to elastic and plastic analyses and the study of nonlinear, large deformation problems such as rubber hyperelasticity and metal forming analysis [31-33]. More recently, Liew et al. [34-36], Wang et al. [37], Cheng and Liew [38] and Zhao et al. [39] also employed the RKPM to undertake various analyses of laminated composite cylindrical panels and rotating cylindrical shells, 
rectangular, laminated composite plates, the modeling of the human proximal femur and twodimensional unsteady heat conduction problems.

Many other variants of meshfree methods can be found in the literature. Sulsky et al. [40] developed a particle-in-cell (PIC) method to study solid mechanics in the free Lagrangian description, which was also extended to form the material point method (MPM) [41]. A partition of the unity finite element method (PUFEM) was introduced by Babuška et al. [42] and further methods, such as the finite point [43], were also devised. The finite point method (FPM) [44, 45] uses the weighted least square interpolation for an approximation of the problem unknowns and uses a stabilization technique in the collocation point method for numerical integration. The radial basis function (RBF) method [46, 47] is another unique approximation method based on the strong form formulation, whereby the use of background cells for numerical integration is avoided. Instead, it uses the radial basis functions to approximate the field variables within the entire domain. Since its introduction, the RBF method has been applied extensively in multiquadric-biharmonic methods [48] and structural mechanics problems [49-51].

The set of meshfree methods reviewed above, based on MLS approximations, generally do not satisfy the Kronecker delta property, and hence essential boundary conditions cannot be directly imposed as in the conventional FEM method. Therefore, they are termed approximant meshfree methods, while another set of meshfree methods that do satisfy this property are known as the interpolant meshfree methods. These sets of interpolant meshfree methods are, in no particular order, now described. The point interpolation method (PIM) was initially proposed by Liu in 2001 [52, 53]. Due to its superior properties, such as its ease of implementation, flexibility and satisfaction of the Kronecker delta function property, the PIM approach and its variants, such as the radial point interpolation method (RPIM) [54] and the smoothed Hermite radial point interpolation method (SHRPIM) [55] have since been applied to solve a wide range of problems in the field of computational mechanics.

Sukumar and his co-workers proposed the natural element method (NEM) [56] and natural neighbor Galerkin method (NNGM) [57] as new variants of the meshfree method. Here, the trial and test functions are constructed using natural neighbor Sibson interpolants, representing a multivariate data interpolation scheme that was initially used in data fitting. These meshfree methods are constructed using popular geometrical and mathematical concepts such as the Voronoi diagram [58] and the Delaunay tessellation [59]. More recently, 
the natural neighbor radial point interpolation method (NNRPIM) has been derived out of a combination between the NEM and the RPIM [60].

Sukumar [61, 62] further advanced the prospects of meshfree methods by formulating maximum entropy approximation polygonal interpolants for solving computational mechanics problems; the Kronecker delta property is satisfied weakly at the boundary and hence the essential boundary conditions can also be imposed, as in the FEM approach. New modifications of the maximum entropy approach, such as the local maximum entropy approximation was proposed by Arroyo and Ortiz [63] and a higher order method based on the local maximum entropy method was developed by Gonźalez et al. [64], while the numerical integration of the weak forms is performed using a similar approach, as in the EFG and DEM methods. Other interesting meshfree methods expounded in the literature include the point assembly method [65], the meshless finite element method (MFEM) [66] and the natural radial element method (NREM) [67].

Another class of meshfree methods that are generally referred to as particle methods is briefly described here. The discrete element method (DSEM) [68], dissipative particle dynamics (DPD) [69], moving-particle semi-implicit (MPS) [70], and generalized finite difference (GFD) [71] all provide outstanding results in terms of handling, with relative ease, complex moving boundaries with scalar and other complexities. The DPD and MPS methods, which originated in the field of molecular dynamics, where each particle moves according to Newton's second law, have been used to simulate systems of particles. These methods have been used extensively in the literature for the solving of a lot of biomechanics related problems.

Some of the main characteristics, advantages, and drawbacks of meshfree methods are briefly summarized below:

a. The shape (or interpolation) functions of meshfree methods can easily have higherorder continuity since the shape functions are mostly constructed by embedding a highly smooth window (or weight) function with a large support domain size. Contrary to this, even the need to construct a $C^{1}$ continuous shape function in the mesh-based methods can cause a serious problem.

b. As far as maintaining the same order of consistency is concerned, numerical results reveal that the convergence of meshfree methods is often considerably better than that of mesh-based methods such as FEM. 
c. Meshfree methods possess nonlocal properties, as every evaluated point in the domain is covered by the multiple shape functions of the node and this property is determined by the size of the compact support domain. In addition, the adoption of a compact support domain can substantially reduce the bandwidth of the meshfree method. Hence, meshfree methods can achieve much higher precision levels than mesh-based methods when used to solve large deformation problems in engineering.

d. Since the meshfree shape function is independent of meshes, it can avoid the burdensome work of meshing and re-meshing associated with FEM when applied to the study of finite deformation, fracture and crack propagation problems.

e. Although the meshfree methods possess superior properties over mesh-based methods, they are often more computationally expensive due to their shape function construction cost. Additionally, the enforcement of boundary condition in approximant meshfree method is not straightforward as in the FE technique since they do not satisfy the Kronecker delta property.

In this review, the mathematical formulation, numerical implementation and programming of these meshfree and particle methods are omitted since the focus of this article is on their applications in bioengineering and biomechanics. However, such details can be found in the following literature [72-75] and the references cited therein.

\section{Applications}

Since the first appearance of the meshfree and particle methods in the literature, their applications have spanned many areas of science and engineering. In this section, we comprehensive discuss their applications in the field of biomechanics, covering key areas such as biological tissues, bone remodeling, heart and cardiovascular mechanics, cell mechanics, blood flow dynamics, human swimming locomotion and bird flights, and some emerging areas such as developmental biology.

\subsection{Biological Soft Tissues}

Biological soft tissues are multiphasic materials, consisting of various amounts of living cells, extracellular matrices and interstitial fluid, with a considerable amount of water. The most prominent attribute of biological soft tissues is their high elasticity; hence, they are popularly referred to as hyperelastic. Another important characteristic is their anisotropic behavior 
(although some may be purely isotropic), which depends on the degree of concentration and structural arrangement of their principal constituents, such as elastin, collagen, and so on. Owing to their strong nonlinearity, their ability to undergo finite deformation, their isotropic or anisotropic nature, and their viscoelastic or hyperelastic behaviors, the choice of an accurate material constitutive model can be very challenging. Examples of the biological soft tissues to be considered in this section include the liver, collagen scaffolding, kidney and skin.

One of the foremost studies on the application of meshfree methods to biological soft tissue simulation was performed by De and his co-worker [76, 77]. In their studies, they presented a novel meshfree modeling technique, called the method of finite spheres, by which they computed the underlying virtual-based medical simulation by enabling the user to interact with physically-based tissue and organ models in real-time using both visual and haptic sensory modalities. Their approach was then applied to study the real simulation of 3D liver tissue palpation assuming a linear elastic behavior by monitoring the tissue deformation and tool tip reaction force. Zhu et al. [78] implemented a point-based simulation framework for minimally invasive surgery using the SPH method.

The MPM approach was employed for the nonlinear modeling of a 3D vascularized scaffold under tension, consisting of growing microvascular fragments embedded in a collagen gel constructed from volumetric confocal image data and discretized with over 13.6 million material points [79]. Since the material properties of collagen gels are nonlinear and viscoelastic, and since there are no available data for the material properties of individual microvessel fragments, an uncoupled compressible neo-Hookean hyperelastic constitutive model was used to represent both the collagen and the microvessels. Sensitivity studies on the effects of grid resolution, material properties, and computational algorithm were also performed.

In a bid to understand the factors that control the extent of tissue damage due to material failure in soft tissues, which may provide a means by which to improve the diagnosis and treatment of soft tissue injuries, the MPM was used to study the failure of soft tissues subjected to large deformation using an anisotropic neo-Hookean hyperelastic constitutive model. Furthermore, the authors adopted a constitutive model that incorporated a strain-based failure criterion. The efficiency of the proposed approach was investigated using simulations of simple tensile mechanical, slab penetration tests considering the scenario of a penetrating injury due to a projectile such as a bullet [80]. Liu and his colleagues [81] also simulated the 
stress wave propagation and subsequent failure evolution of hard-soft material interaction under impact loading by applying force to layers of different materials using the MPM approach.

Lim and De [82, 83] improved upon their previous studies [76, 77] to account for the geometrically nonlinear tissue response in the human kidney by performing real-time surgery simulations. The problem geometry was obtained by way of image segmentation using the point collocation-based method of finite spheres in which MLS functions are compactly supported on spherical subdomains and a point collocation technique is employed as the weighted residual scheme. In order to overcome the problems of needle insertion inaccuracy, difficult motion planning and the need for remeshing during real-time minimally invasive surgical simulation, $\mathrm{Xu}$ et al. [84] presented a meshfree framework for bevel-tip flexible needle insertion through soft tissue by using two separated sets of nodes to represent the needle and the soft tissue. In their simulation, additional nodes were added to the tissue by exactly following the needle's kinematics or dynamics during insertion, while the interactions between the needle and tissue were calculated and simulated through their influence domains. Reasonable results were obtained. However, the problem was grossly simplified as only elastic, isotropic and linear soft tissue with a simple geometry was considered.

Zhu et al. [85] also proposed a hybrid particle and surface-based method to model the elastic behaviors of organs with complex surfaces in the surgical environment using the SPH method, due to the simulation resolution issues associated with using pure particle-based methods. Hieber et al. [86] proposed a remeshed SPH approach to achieve improved accuracy in the simulation of the mechanical behavior of human liver and kidney, using a linear viscoelastic material model. In their study, they also established a unified formulation of fluid-structure interaction based on particle methods. For the sake of improved accuracy, better real-time, stability and ease in performing virtual real-time surgery simulation, several other modified or hybrid meshfree and particle methods have been proposed in the literature [87-89].

By means of a meshless total Lagrangian adaptive dynamic relaxation (MTLADR) algorithm, which is an extension of the MTLED algorithm (to be introduced later), Jin and her coworkers performed the 2D [90] and 3D [91] modeling of soft tissue cutting in surgical simulation. They predicted the steady-state deformation of soft tissue at all stages of cutting, while cutting-induced discontinuities were modeled solely through changes in nodal domains of influence. The accuracy and computational cost effectiveness of the proposed algorithm 
were compared with that of the established nonlinear solution procedure using the commercial FE code, ABAQUS. Abdi et al. [92] studied the dynamic and real-time large deformations of a 3D linear viscoelastic model of human spleen subjected to a time-varying compressive force exerted by a surgical grasper within a meshfree EFG based algorithm with a 3D linear basis function, a cubic spline weight function, and MLS shape functions whose essential boundary condition was imposed using the penalty method.

Cao et al. [93] proposed a meshless model based on the multi-subdomain radial basis function and the method of fundamental solution (RBF-MFS) to explore bioheat transfer problems such as the prediction of temperature distribution in skin tissue, involving different materials and/or multi-connected regions, like normal tissue, tissue with tumor and burnt tissue. A schematic of the 2D calculation geometry is presented in Fig. 1 below. The wellknown Pennes equation, which involves the effects of blood perfusion and metabolic heat generation, is used to simulate the thermal behavior of biological tissue [93]:

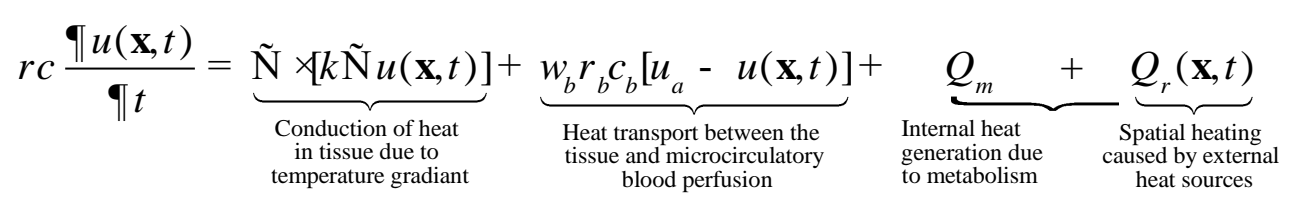

where $r, c$ and $k$ are the density, specific heat, and thermal conductivity of the tissue, respectively; $w_{b}, r_{b}$ and $c_{b}$ represent blood perfusion, density and specific heat of blood, respectively. $u_{a}, u(\mathbf{x}, t)$ and $Q_{m}$ denote the constant arterial temperature, tissue temperature, metabolic heat generation, and heat source due to spatial heating, respectively. 


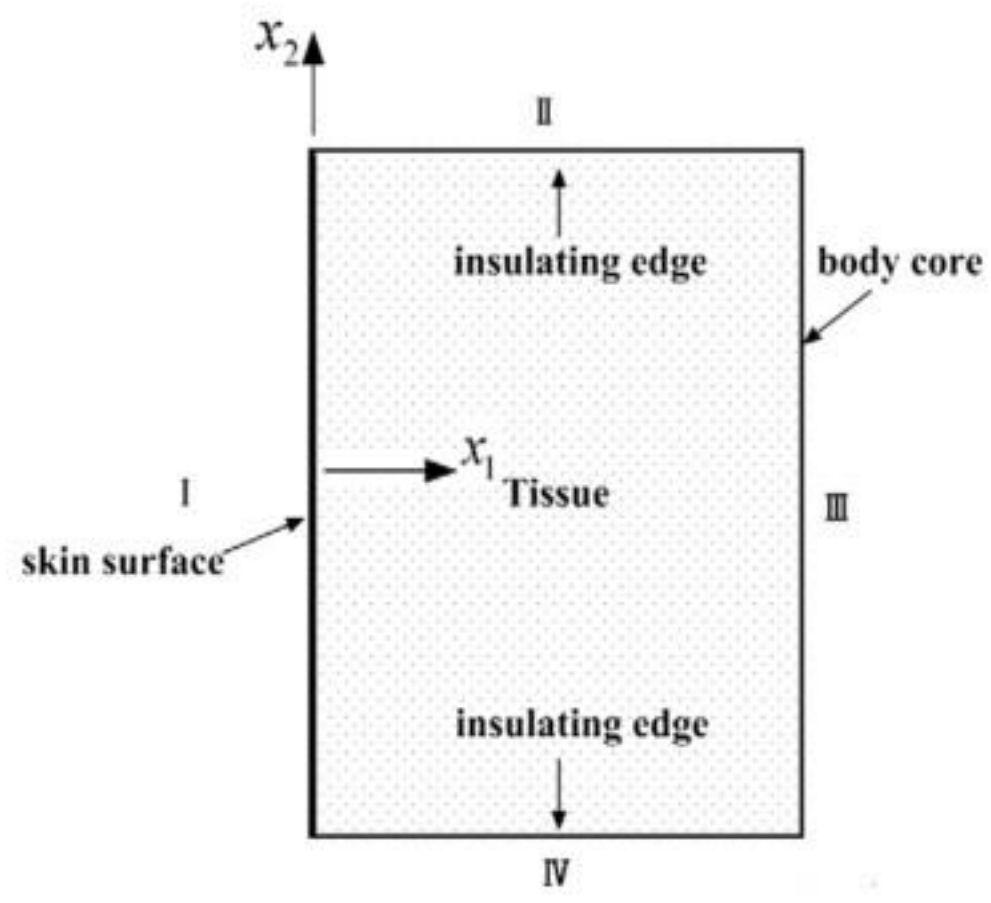

Fig. 1 Illustration of the computational domain for a 2D skin model built on a rectangular area [93].

The following boundary conditions and initial condition are applied to the four boundaries, as shown in Fig. 1:

- Dirichlet boundary condition: $\quad u(\mathbf{x}, t)=\bar{u}(\mathbf{x}, t) \hat{\mathrm{I}} \mathrm{G}_{u}$

- Newman boundary condition: $\quad q(\mathbf{x}, t)=\bar{q}(\mathbf{x}, t) \hat{\mathrm{I}} \mathrm{G}_{q}$

- Convective condition: $\quad q(\mathbf{x}, t)=h_{e}\left[u(\mathbf{x}, t)-u_{e}\right] \hat{\mathrm{I}} \mathrm{G}_{c}$

- Initial condition: $\quad u(\mathbf{x}, 0)=u_{0} \hat{\mathrm{I}} \mathrm{W}$

where $q$ represents the boundary normal heat flux defined as $q=-k \rrbracket u / q n$ and $n$ is the unit outward normal to the boundary $\mathrm{G}$ of the domain of interest $\mathrm{W}$. $u_{e}$ denotes environmental temperature. The time variable can be handled using the Laplace transform or the finite difference approach.

Tao and his colleagues solved various linear transient skin bioheat transfer problems using the meshfree method by combining the Laplace transform method and the RBF-MFS method in order to reduce the overall computation time [94]. Other approaches were also formed from the coupling of the method of fundamental solution (MFS) and either the dual reciprocity method (DRM) [95] or the operator splitting method (OSM) [96], to solve nonlinear steady state and transient bioheat transfer problems using a $2 \mathrm{D}$ nonlinear skin model with a temperature-dependent blood perfusion rate within the RBF meshfree 
framework. For details on the nonlinear skin bioheat model, interested readers can refer to $[95,96]$ and the references therein.

Jamil and $\mathrm{Ng}$ [97] proposed a new meshless radial basis collocation method (RBCM) for the heterogeneous conduction and simulation of the temperature inside biological tissues using an approximation function developed using inverse multiquadratic (IMQ) radial basis functions (RBFs). A weighted collocation method was used to overcome problems due to the nonlocality of the RBFs and errors at the boundaries, domain, and interfaces in order to obtain exponential convergence. Bourantas et al. [98, 99] extended the Pennes bioheat equation to incorporate water evaporation, tissue damage, and temperature-dependent tissue properties during tumor ablation, while the conductivity of the tissue was treated as a local function in order to simulate local variability due to the existence of the usually unclear interfacing of healthy and pathological segments. The meshless point collocation was implemented to solve the resulting transient bioheat problems for 2D and 3D problems.

In [100], the authors implemented an SPH approach to solve the non-linear Pennes bioheat transfer equation for skin tissue. Here, the Cattaneo and Vernotte (CV) model was incorporated to overcome the paradox of an infinite sound speed, using the dual-phase-lag (DPL) model for the heat flux vector, while capturing the non-linear behavior of the model using the temperature-dependent conductivity. Erhart et al. [101] proposed an evolutionarybased inverse approach for the identification of non-linear heat generation rates in living tissues by using a localized meshless method to analyze Pennes' bioheat equation, while the rates of heat generation within the domain of interest were obtained using genetic algorithm optimization. A patient-specific meshfree approach was proposed in [102] for numerical modeling of the mechanical deformation of tissues in the female pelvic floor during childbirth.

Pyo et al. [103] implemented a physically-based nonrigid registration method using the SPH for hepatic metastasis volume-preserving registration between follow-up liver computed tomography (CT) images by discretizing the liver and hepatic metastasis as a set of particles carrying their individual physical properties, where the hepatic metastasis represented particles were stiffer, as shown in Fig. 2. In their studies, an automatic liver segmentation method based on a level-set algorithm was adopted to achieve optimal estimation of the initial liver shape, and faster and more robust segmentation of the liver, while the metastasis candidate regions were automatically detected in the source image instead of segmentation, 
due to the ambiguous boundary of, and large variability in, the shape, size, and location of the liver.
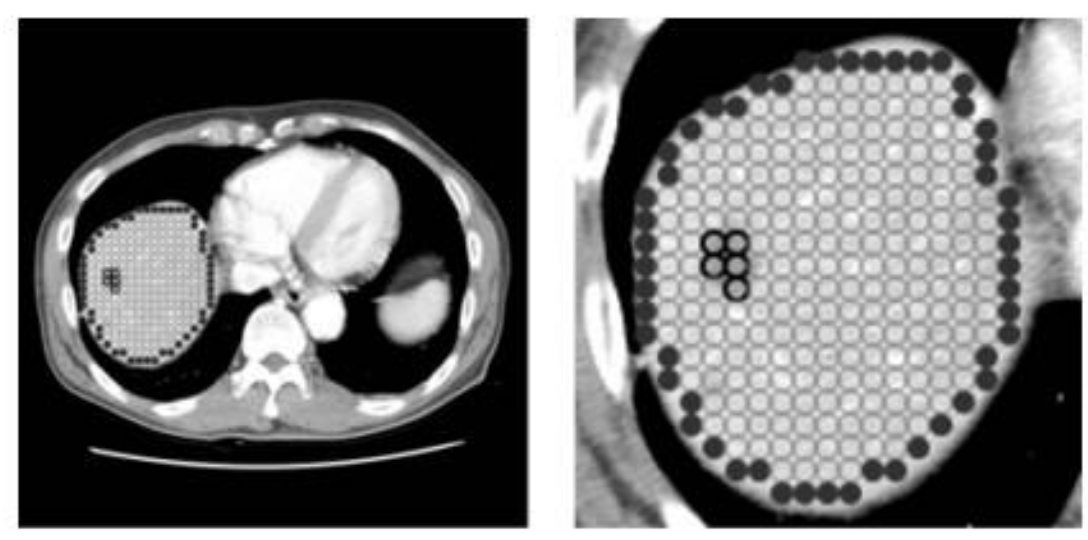

Fig. 2 Particles placed in the initial shape of the liver (left), and its magnified view (right). Particles of a fixed size are regularly placed in the liver. Light-gray-lined, black-lined and black-filled particles represent normal liver particles, metastasis particles and boundary particles, respectively [103].

Naeeni and Haghpanahi [104] extended the application of meshfree methods to elastography (i.e. the measurement and visualization of the mechanical properties of human organs by applying a mechanical stimulation and then imaging the resulting local displacements), by way of studying the deformation of an elastic non-homogenous phantom using the EFG method in the plane strain state with respect to experimental conditions. The numerical results were validated experimentally in order to calculate the deformation of the phantom surface via a digital imaging processing technique in MATLAB and were in perfect agreement. Wachowiak et al. [105] studied the deformation of soft tissues using the compact support radial basis functions (CSRBFs). Data obtained from the 3D prostrate imaging of needle insertion during the implantation of radioactive seeds for brachytherapy were used to demonstrate the efficacy of the proposed method.

A physical-based meshless method for soft tissue deformation has also been proposed [106]. An et al. [107] recently employed a CSRBF-based meshless method for photon propagation model of fluorescence molecular tomography, which is a powerful imaging modality for the research of cancer diagnosis, disease treatment and drug discovery. In order to analyze the performance of their proposed meshless method, the authors designed some numerical mouse studies to validate the simulated surface fluorescence distribution, and in vivo mouse studies to evaluate the tomographic reconstruction. Aras et al. [108] proposed an analytic meshless enrichment function for handling material discontinuities such as cuts in interactive surgical 
simulation. Zhou et al. [109] recently proposed a 3D RBF model based on Marquardt's algorithm for numerical modeling of the real-time deformation of human soft tissues.

In [110], the authors used a 3D SPH formulation to simulate the penetration impact of a steel sphere on soft tissue composed of $20 \%$ ballistic gelatin material. Nooshabadia et al. [111] and Dehghan et al. [112] employed the EFG method in comparison with FEM for the large deformation of kidney, liver and gallbladder during interaction with surgical tools/grasper. The two studies concluded that the meshfree method performed better than the FEM. A similar study on the large deformation behavior of liver during surgery was carried in [113] using a new deformation model which incorporates Kelvin viscoelasticity into the RPIM formulation. Palyanov and his co-workers [114] recently presented an open source software package called Sibernetic based on the predictive-corrective incompressible SPH method designed for the physical simulation of biomechanical matter (membranes, elastic matter, contractile matter) and environments (liquids, solids and elastic matter with variable physical properties).

Grabski et al. [115] formulated the identification of the time-dependent blood perfusion coefficient as an inverse problem in which the bio-heat conduction problem is transformed into the classical heat conduction problem. The transformed inverse problem was then solved using the MFS approach together with the Tikhonov regularization. A real-time dissection (or cutting) approach for organs such as liver, spleen and gallbladder using hybrid coupling of geometric metaballs and physics driven meshfree method based on MLS shape functions was recently presented by Pan et al. [116]. A combined application of continuum damage theory and SPH technique was proposed by Rausch and his co-workers [117] to model the damage and failure of soft tissues. Soleimani et al. [118] presented a 3D computational model to examine biofilms in a multi-physics framework using the SPH technique based on a continuum approach. The authors employed the SPH technique since it is uniquely robust in capturing the interface-related processes of biofilm formation.

\subsection{Bone Remodeling and Dental Studies}

Bone is an inelastic organ, which forms the vertebral skeleton; it is responsible for supporting and protecting several other internal organs of the body. It also acts as "factory" where red and white blood cells are produced, while also enhancing movement and storing essential minerals. Generally, bones are known to have complex structures, both internally and externally. They are formed in various forms and sizes according to their required and 
specific functions. Despite their lightweight, they are strong, hard and perform various functions. From the biomechanics point of view [119], bone remodeling is a complex behavior, which entails the ability of bone to change and grow in order to adapt itself to the applied load history. This behavior is believed to occur as a combination of two unique processes: the bone's ability to change its tissue density according to mechanical demands (internal bone remodeling) and the bone's ability to change its shape for enhanced adaptation to mechanical loads (external bone remodeling).

In 1892, Julius Wolff [120] first observed the relationship between bone structure and applied loads, and concluded that it was mainly associated with the evolution of apparent density. Following Wolff's pioneering work, this variable (i.e. apparent density) and relationship have since been used by many models in the literature to represent the bone remodeling state. It has also been observed that, depending on the model used, the mechanical stimulus responsible for change may differ, while many of the diverse stimuli have been defined as a function of strain, stress or strain energy [121]. Garcia et al. [119] performed the numerical two-dimensional simulation of proximal femur internal bone modeling using a new damage mechanics-based model, which comprised a generalization of standard continuum damage mechanics (CDM) to living materials [121]. Here, the authors proposed a modified natural element method (NEM), called the $\alpha$-NEM, which allowed the actual shape of the geometry to be obtained from a set point without specifying the boundary of the domain.

Liew et al. [34] employed a meshfree method based on the reproducing kernel particle approximation for the simulation of the human proximal femur. Their formulation considered treatments of nonconvex boundaries and material discontinuities in the bone structure, and a pre-processor was developed for the generation of discretized scatter particle models. Fig. 3 below shows the geometry, boundary, and loading conditions of a human proximal femur model (left) and one of the meshless analysis models discretized with 316 nodes (right). 

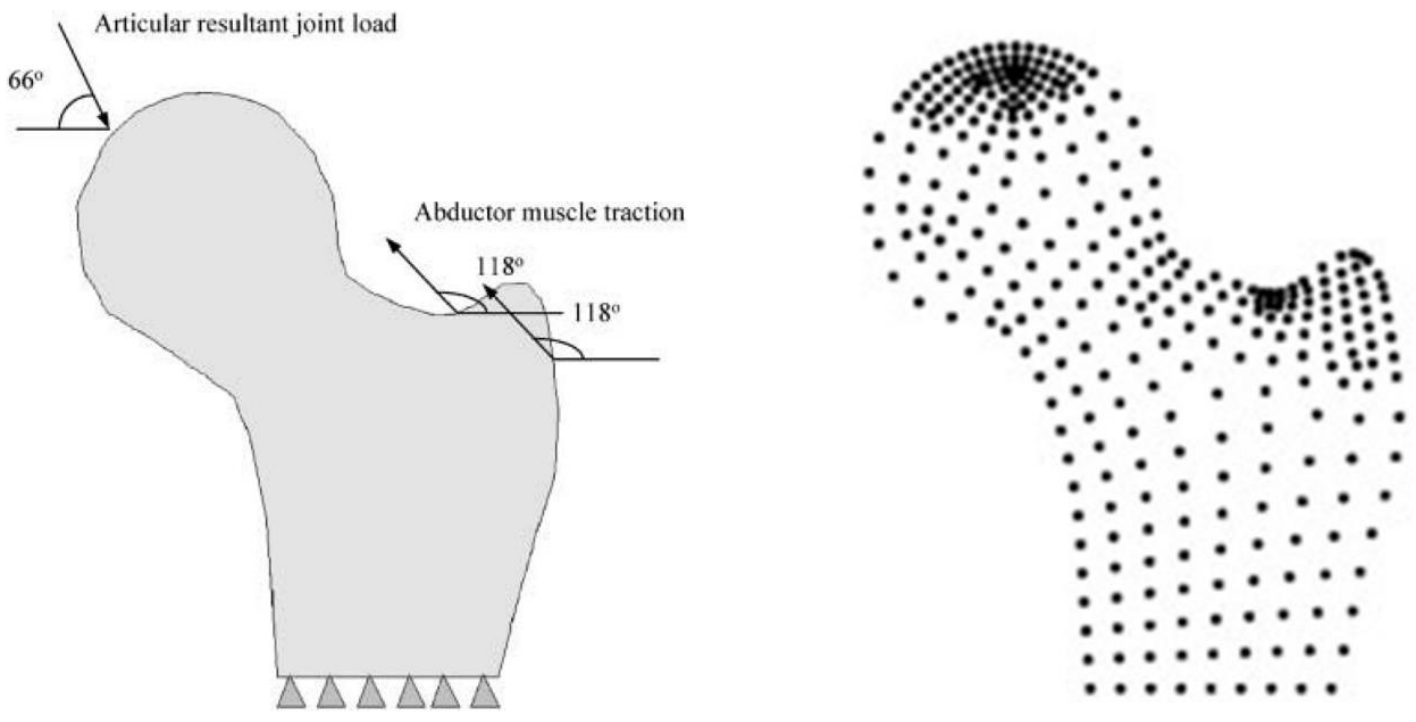

Fig. 3 Geometry, boundary and loading conditions of a human proximal femur (left) and a meshless analysis model discretized with nodes (right) [34].

Numerical examples have been used to study certain stress distribution phenomena in the human proximal femur with a consideration of the detrimental effects of infarction, aging, and stress variations. Using the femur bone, the hypotheses that low strain fields arise due to age-related pore distributions causing bone absorption, and due to bone remodeling features at the particle level, have been studied using the SPH approach [122, 123]. Based on their previous studies [119], Doblaré et al. [124] analyzed the convenience and possible advantages of using meshless methods in numerical simulations within the field of biomechanics. With an interest in NEM, they considered its application to the simulation of adaptive bone remodeling based on the CDM principles by identifying the local "damage" variable with bone tissue porosity, by way of a simulation of hyperelastic tendons under large strains and a simulation of poroelastic articular cartilage. From their studies, it was concluded that the meshfree method performed with a greater degree of accuracy than traditional FE simulations. A decrease in bone strength as a result of a decrease in bone mass and a deterioration of bone microstructure due to osteoporosis (a skeletal disease), and as a result of a fracture of the trabecular bone, have been studied using a 3D meshless model generated directly from CT imaging data [125]. 
Taddei et al. [126] also implemented a meshless cell method (MCM) approach for subjectspecific strain prediction in bones from CT data, which compares well with results obtained from experimental studies. The entire process of microcrack propagation in the cortical bone, including the propagation of microcracks towards the osteon, around the osteon and out of the osteon, with or without the healing property of the bone, was studied by Deng et al. [127]. This was achieved by using a meshfree method to solve a nonlocal elastic theory derived from the atomistic nonlocal nonlinear multiscale field theory. Uscilowska and Fraska [128], using the MFS-based meshfree method and a procedure based on Picard iteration, estimated the torsional stiffness of long bones while considering the bone as a functionally graded material (FGM), whose shear modulus is a function of geometrical variables.

Belinha and his co-workers [129-131] proposed a novel anisotropic material law for the mechanical behavior of bone tissues based on experimental data, which permits the correlation of the apparent bone density with the obtained level of stress. By using the proposed material law, a biomechanical model for predicting bone density distribution was developed, based on the assumption that the bone structure is a gradually self-optimizing anisotropic biological material that maximizes its own structural stiffness. Meanwhile, the NNRPIM, a variant of the PIM meshfree method, was used to obtain the strain and stress fields required in the iterative remodeling process of the femur, calcaneus bones and implants. Following the success recorded in their previous studies using the NNRPIM meshfree method, they more recently studied bone density distribution in the vicinity of femoral implants using a topology optimization model based on deformation energy methods [132]. The bone tissue remodeling algorithm is presented in Fig. 4 below. 


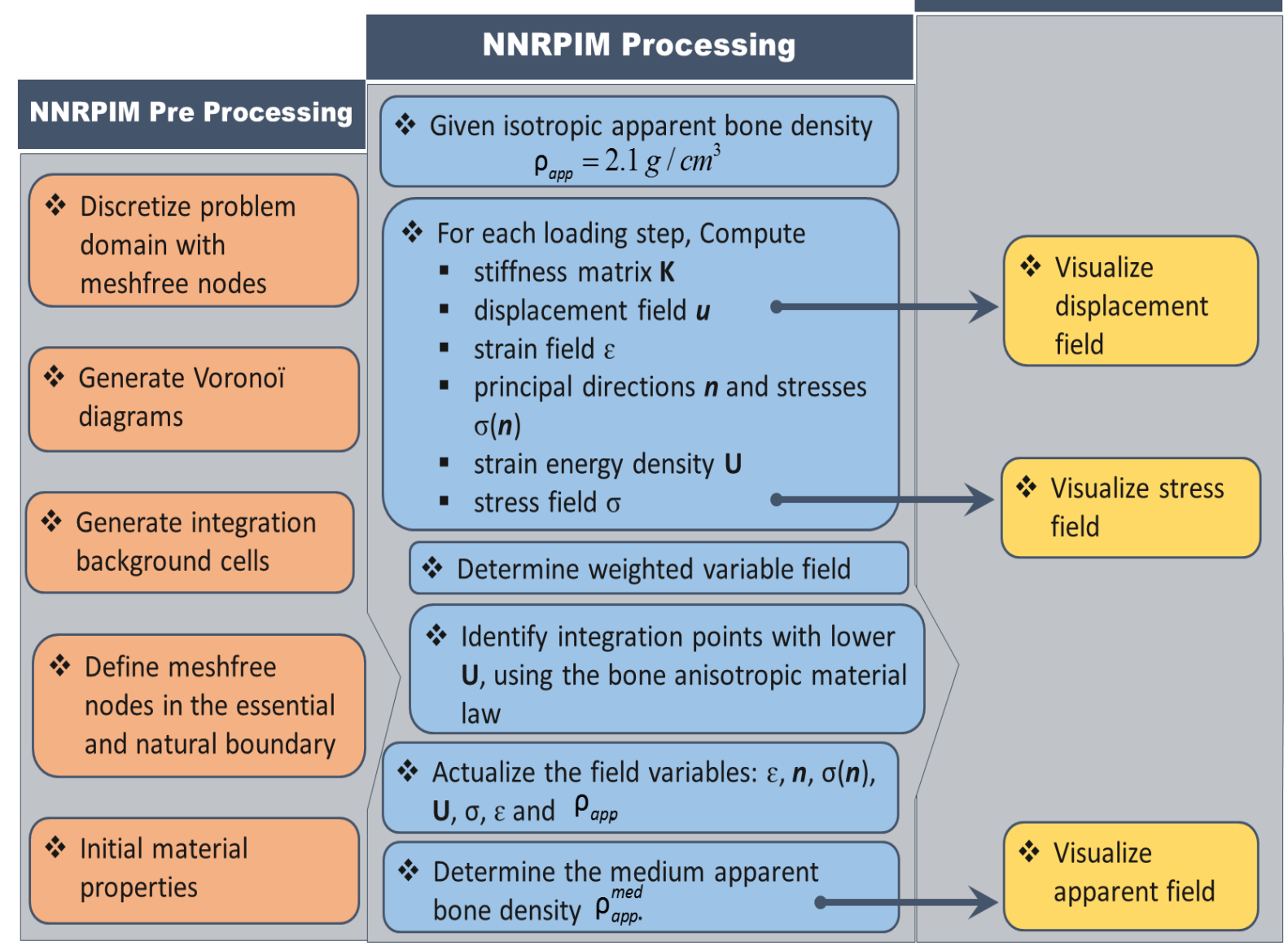

Fig. 4 Bone remodeling algorithm based on the NNRPIM meshless method (modified after [131]).

Owing to the complexity involved in the bone healing process and the limitations of meshing and remeshing in the FEM, Grivas and his co-workers implemented a meshless Local Boundary Integral Equation (LBIE) method for cell proliferation predictions in bone healing by solving a cell diffusion problem [133]. They also analyzed the nonlinear Fisher transient diffusion equation [134] for the 2D modeling of a fractured bone by incorporating initial cell concentrations at the periosteum, the marrow, and between the bone and the callus (at the fractured end). Yang $[135,136]$ utilized high-resolution medical images to develop an imagebased strong form collocation procedure using a gradient reproducing kernel approximation, for the biomaterial modeling of bone fracture, the bone remodeling process and the design of bone-implant systems, as well as the microstructure modeling of trabecular bone.

More recently, interest in the application of various numerical methods (meshfree methods included) to dentistry and food processing has grown significantly. Cleary and his colleagues [137-139] modeled the process of fluid flow and the breakage of various kinds and shapes of food by teeth in the oral cavity using a coupled SPH-biomechanical model. In their works, 
realistic 3D geometries and motions of the jaws and tongue were incorporated into simulations of fluid flow, biting, and the chewing of foodstuffs. Saliva and liquid food were represented as a Newtonian fluid, and the solid foodstuffs were represented as either elastoplastic or brittle elastic solids. In another study, a 3D dynamic SPH mastication model was proposed to predict how consumers perceive food, based on food breakdown and release of flavor processes [140]. Ho et al. [141] performed a 3D swallowing simulation using the SPH method while the haptic rendering of dental filling materials using the SPH technique has also been implemented [142].

Andrade et al. [143] performed the elastic-static modeling of dental implants using an NNRPIM meshless method for possible application to bone using a 2D model composed of the occlusal material, a metal framework, an abutment and implant screw, and cortical and trabecular bone. The model was subjected to vertical and horizontal loads with displacement boundary conditions in the boundary of the bone. Fig. 5 below shows the 2D model of the dental implant, the boundary and loading condition as well as the meshless node discretization of the model.

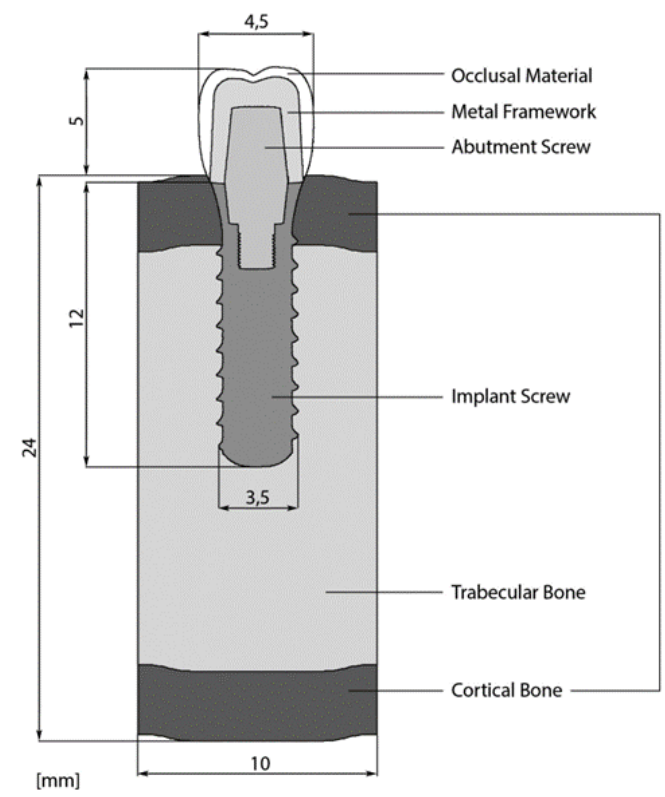

(a)

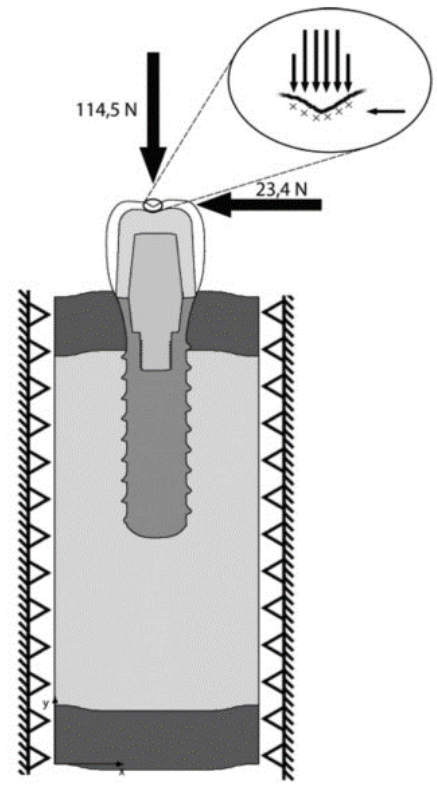

(b)

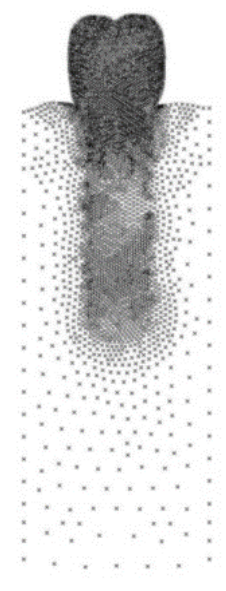

(c)

Fig. 5 Schematic diagram showing (a) a 2D model of a dental implant, (b) boundary and loading conditions, and (c) meshfree node distribution [143].

The results obtained from their studies show that a higher level of cortical bone stiffness provides lower effective stresses in the cortical bone and higher stresses in the implant. In 
addition, a higher level of occlusal material stiffness provides lower effective stresses in the implant, in the abutment, in the metal framework and in the cortical bone. Although the results obtained are undoubtedly insightful, it is believed that more conditions, such as bone material anisotropy, inelasticity, and so on, should be considered for a more realistic simulation of implants in the in-situ condition.

Furthermore, Belinha et al. [144-146] predicted bone density distributions on the mandible and maxillary bones as a result of the presence of dental implants, by means of a topology optimization model built on the deformation energy method using Carter's remodeling algorithm [147] within the NNRPIM meshless technique framework. Also, using the NNRPIM meshless method, Duarte et al. [148, 149] studied a prosthetic system consisting of two implants connected with a bar using a 2D linear elastic stress-strain model. The anisotropic behavior of the cortical bone was simplified and implemented as an isotropic condition; however, the obtained results were similar to those reported in the literature using FEM in terms of showing that a stiffer bar material induces higher stresses on the bone tissue and lower stresses on the implants. Yamaguchi et al. [150] compared the dynamic twodimensional FEA and moving particle simulation (MGPS) while assuming a plane strain condition in the modeling of human enamel on a reduced scale. The MGPS was able to produce results that were highly correlated to FEA, with the possibility of further development and application to more complex biomechanics problems.

Recently, Moreira and his co-workers [151, 152] numerically analyzed the maxillary central incisor using the NNPRIM method, by performing a complete elastostatic analysis of the incisor/maxillary structure and then a non-linear iterative bone tissue remodeling analysis of the maxillary bone surrounding the central incisive, based on Carter's model. The computational model used in their studies was obtained from a computerized axial tomography (CAT) scan, which was then discretized using irregular nodes. Tavares et al. $[153,154]$ performed a numerical analysis of tooth restoration using the NNRPIM meshless method based on a 2D model constructed from a clinical X-ray image of an upper molar tooth with a restoration. They observed that transverse loads from activities within the oral cavity induce high shear stresses in the intervention zone, leading to a recurring failure of the restoration. In a more recent study, Belinha et al. [155] numerically examined the remodeling of the bone tissue surrounding the femoral stem, aiming to predict the necrosis of the femoral head and understand the mechanical solicitations causing the pathology, using the NNRPIM 
meshless method. The NNRPIM technique has also been employed to study the free vibration behavior of the cupula in the inner ear [156].

\subsection{Cartilage, Muscles and Ligament Modeling}

Unlike the FEM, meshfree methods based on MLS approximation and multi-quadric (MQ) functions possess high continuity, hence the computation of higher order derivatives does not require extra interpolations. This is another significant advantage of the meshfree method, which cannot be ignored. In 2002, Hon et al. [157] presented an efficient meshfree numerical algorithm using the multi-quadric radial basis function (MQ-RBF) with a direct collocation method to simulate a two-dimensional triphasic (i.e. consisting of three phases: solid, water and ion) model of charges and hydrated soft tissues. The intrinsic incompressibility of the continuity equation was considered and solved directly without the use of any penalty function. Numerical studies on the reaction of articular cartilage in a synovial joint subjected to mechanical loading and electrochemical effects were carried out under plane stress, plane strain, and axisymmetric conditions to show the accuracy of the proposed method. The results obtained show a great deal of accuracy. However, for the axisymmetric case using a domain decomposition method, an ill-conditioning problem arises due to the full matrix resulting from the use of the global RBF method.

Marai et al. [158] proposed a meshless incompressible height-field cartilage model to capture the physical properties important for estimating the shape, contact area and the deformation magnitude of cartilage at each articulation. They used a non-invasive method for estimating individual-specific cartilage maps directly from in vivo kinematic data and computed tomography $(\mathrm{CT})$ volume images. They further proposed an algorithm by which to compute cartilage surface deformations. Boyer and his colleagues implemented a 3D fibril-reinforced poroviscoelastic model using the SPH method to simulate articular cartilage within the hip joint [159] and cartilage deformation [160]. Recently, Cyr and Maletsky [161] implemented a multi-dimensional description of knee laxity, which is a product of the individual ligament structures that provide constraint for multiple degrees of freedom, using a meshfree radial basis function method.

Chen et al. [162] established a 3D image based model of skeletal muscles using the nonlinear RKPM meshfree method formulation for hyperelasticity. The authors constructed their simulation model using pixel data obtained from medical images while the material properties and muscle fiber direction used as input at each pixel point were obtained by way 
of diffusion tensor imaging (DTI). Lastly, they adopted a multiphase multichannel level setbased segmentation framework for individual muscle segmentation using magnetic resonance images (MRIs) and DTI. Valizadeh et al. [163] implemented a 3D patient-specific leg-muscle pixel-based model using a coupled isogeometric analysis (IGA) and the RKPM meshfree discretization approach. It is noteworthy that the coupled IGA-RKPM approach was able to preserve the geometric exactness of IGA, circumvent the need for global volumetric parameterization of the problem domain, and achieve arbitrary-order approximation accuracy while maintaining the higher-order smoothness of the discretization.

Pena et al. [164] employed a 3D finite-strain damage model to study the finite deformation of visco-hyperelastic isotropic fibrous (or fiber reinforced) soft tissue within the NEM approach. One significant contribution of this study is the implementation of a constitutive model that can account for the anisotropic behavior of fibred materials, isothermal processes using unique decoupled representations of the strain-energy density function, anisotropic viscoelastic-damage effects, and the material and geometric elements of the consistent stiffness matrix. The accuracy and validity of the model were tested using various standard tests before being applied to the study of damage in a human ligament whose geometry was formed using cross-sectional contours which were manually digitalized from nuclear magnetic resonance images and whose curves were imported into a commercial code IDEAS.

Following the approach reported in [164], Doweidar et al. [165] performed a comparison of implicit and explicit natural element methods in large strain problems through the modeling of the human lateral collateral ligament and knee (i.e. hyperelastic quasi-static fibered materials under large strains). The surface geometries of the ligaments were reconstructed from a set of MRI images while those of the femur, fibula, and tibia were reconstructed from CT images. They concluded that the implicit NEM solver could encounter numerical difficulties in converging to the correct solution when solving problems involving large element deformation, highly non-linear elasticity, stress concentration or changing contact between surfaces, which increases the computational cost in terms of computing the tangent stiffness matrix and solving the system of equations. In the explicit approach, the natural element equations are reformulated, such that they are solved directly without iterations. This implies that the explicit method is more robust in finding solutions and requires less memory to handle large and complicated models. 
Boselli and his colleagues [166, 167] employed a combination of the multilayer MFS approach and the force coupling method for numerical investigation of the fluid dynamics of benign paroxysmal positional vertigo or canalithiasis conditions affecting the semicircular canals of the inner ear by solving the Stoke flow equations with finite-size particles. In [168], the authors employed a block greedy-QR algorithm that exploits the robustness of the multilayer MFS approach in a multilevel fashion and alleviates the over-head of multiple source layers thereby allowing the multilayer MFS to outperform the monolayer MFS.

\subsection{Heart and Cardiovascular Mechanics}

In recent years, there has been a considerable increase in the number of research papers focusing on employing the numerous potentials and advantages of meshfree methods in heart mechanics and other cardiovascular related studies. These studies are briefly reviewed in this section, with a particular interest in their contributions to the field of computational cardiovascular mechanics. The relevance and advantages of meshfree methods to medical image analysis problems, such as physically motivated multi-frame motion analysis, nonrigid motion recovery and inter-object image registration, were studied by Liu and Shi [169]. They implemented the EFG method using the cubic spline weight function and imposed essential boundary conditions via the penalty method, to analyze a biomechanically constrained multiframe heart motion through optimal state-space estimation using two varieties of data constraints: the magnetic resonance (MR) tagging images and the MR phase contrast images. The result obtained shows that the meshfree method is more computationally effective and accurate than the well-known FEM.

Similar to [169], the authors in [170] investigated the use of anisotropic spatial constraints in enforcing spatial regulations on myocardial behavior as well as the spatial filtering of image data measurements. Other related studies, such as the applicability of the composite material model to the myocardium in a cardiac motion recovery experiment (where the matrix is the collagen and the reinforcements are the muscle fibers [171]) and the shape recovery and motion tracking of the left ventricles [172], have also been reported. Shi and his co-workers, using the EFG meshfree method, undertook an individualized active cardiac dynamics and image analysis based on the cardiac physiome model for the imaging of $3 \mathrm{D}$ cardiac electrical activities from body surface potential maps (BSPM) [173]. This approach was further used for the recovery of subject-specific deformation from MRI, and in integrating functional and structural images for simultaneous cardiac segmentation and deformation recovery. 
Wang and Ruby extended the application of the meshfree method of fundamental solution (MFS) to potential inverse electrocardiography (PIE) problems involving the reconstruction of epicardial potentials from measured body surface electrocardiograms and heart-torsion geometry [174, 175]. Li et al. [176] implemented a meshless FEM approach for the solving of the electrocardiogram (ECG) forward problem. A coupled meshfree-BEM approach was proposed by Wang et al. [177] for electrocardiographic simulations involving personalized heart-torso structures, volumetric myocardial transmembrane potential (TMP) dynamics and TMP-to-body surface potential (BSP) mapping. This approach was then used to study normal cardiac conditions, different bundle branch block (BBB) conditions (by removing corresponding sites of earliest excitation in the ventricles), and ectopic activities (i.e. ventricular pacing).

A fast motion tracking method based on the meshfree kernel method for tagged MRI-based quantitative cardiac analysis was proposed by Chen et al. [178]. Chen and his colleagues also implemented a 3D cardiac motion and strain estimation approach, integrating the robust point matching (RPM) and meshfree deformable models [179-181] by using tagged MR images. A similar study involving 3D cardiac motion reconstruction from CT data and tagged MR images has also been performed [182, 183]. Stabilized beating heart surface motion estimation, necessary for robotic surgery, has also been studied [184, 185]. In [186], the authors proposed a voxel-based adaptive meshfree method for cardiac electrophysiology simulation by solving the modified FitzHugh-Nagumo (FHN) equations. Pashaei et al. [187] proposed a fast estimation of electrical activation time in the ventricular wall by approximating the path and elapsed time that an electrophysiological signal would need to travel over two points in any given $3 \mathrm{D}$ geometry. The EFG method has also been proposed to simulate the propagation of myocardial electrical activation in canine ventricular and human heart models, constructed from a digitized virtual Chinese dataset without explicit mesh constraints using an FHN monodomain model [188].

The mechanical behavior of mitral valve opening was studied by way of a particle-based SPH approach using the fluid-structure interaction (FSI) model [189]. Yu et al. [190] implemented a multiscale model of calcium dynamics in ventricular myocytes with realistic transverse tubules using both the meshfree method and FEM at different scales. Here, the meshfree method was used to predict spatial-temporal calcium concentration in a large domain while the FEM was implemented to treat the system of nonlinear reaction-diffusion equations on 
the geometrical model. This system of equations has also been computed in a similar study using the local radial basis function collocation method (LRBFCM) [191].

The use of SPH has been extended to the study of the pulsatile flow in the heart's left ventricles [192], and to the evaluation of shear stress accumulation in blood components in normal and dysfunctional bileaflet mechanical heart valves [193]. More recently, Skatulla and his co-workers studied how gel injections influence the mechanics and performance of the left ventricle with myocardial infarction during a full heartbeat using the EFG method [194]. They also proposed an EFG based reduced order method (ROM) called the proper orthogonal decomposition with interpolation (PODI) in a bid to reduce the huge overall computation time associated with complex and nonlinear [195, 196] and patient-specific [197] real-time simulations in cardiac mechanics. Lluch et al. [198] employed the SPH method for image-based cardiac electrophysiological modeling by solving the macroscopic biophysical mono-domain model Mitchel-Schaeffer together with a diffusion term on a left ventricle.

Sack et al. [199] employed the EFG method for the simulations of the left ventricle undergoing passive filling by modeling the cardiac tissue with fibers as one-dimensional Cosserat continua instead of using the anisotropic strain energy functions which do not elucidate on the complex heterogeneous material composition of cardiac tissues. A meshfree MFS method involving the combination of live confocal imaging and computational fluid dynamics was employed by Boselli and Vermot [200] to analyze the wall dynamics, the flow field, the wall shear stress and overcome difficulties related to live imaging of blood flow in the developing zebrafish heart. In a more recent study, Mao et al. [201] presented a fullycoupled fluid-structure interaction study for transcatheter aortic valve dynamics using SPH technique. The approach presented by the authors is able to assess the hemodynamics responses of bio-prosthetic heart valves (BHVs) and blood flow in the left ventricle.

\subsection{Brain Mechanics}

There is no doubt that the brain is one of the most delicate, complex, and important organs in living animals and humans. Even slight damage to the brain due to injury as a result of impact, exposure to radioactive radiation, and so on, could lead to loss of life or sanity. In this section, we review various studies involving the use of meshfree methods in relation to the brain's electric and magnetic potential distributions, deformation, real-time surgical simulations, and indentation. 
In 2005, von Ellenrieder et al. [202] proposed a finite points mixed method (FPMM) which used a collocation technique to discretize the quasi-static Maxwell equations and compute the electroencephalography (EEG) forward problem solution. This was undertaken in order to obtain the electric potential distribution generated by a source of electric activity inside the brain, using both a three-layer model representing the brain, skull and scalp and a more detailed and accurate $M$ layers model which included cerebrospinal fluid and differences between gray and white matter. The results obtained show that the meshless method performed better than BEM and FEM in terms of order of accuracy, the sparseness of assembled matrices, computation cost, and so on. This study was based on previous work by the authors, who aimed to understand the effect of perturbations in the geometry of the head model on the accuracy of EEG source parameter estimation [203].

Peng et al. [204] recently studied the effect of head models and dipole source parameters on EEG fields using a point least squares (PLS) based meshless method. Similar to the EEG forward problem, the magnetoencephalography (MEG) forward problem, which involves computing the scalp potential and magnetic field distribution generated by a set of current sources and analyzing the complex activation patterns in the human brain, was studied using the SPH method, by Ala and co-workers [205, 206] and the MFS method via the method of particular solutions (MOPS) [207]. In their studies, the three-layered and multilayered model was used, the magnetic field was computed by way of the Biot-Savart law and numerical experiments were carried out in a realistic single-shell head geometry. They also formulated the coupled M/EEG forward problem by means of Maxwell's equations [208]. The results obtained were shown to be in satisfactory agreement with analytical solutions. A novel approach for estimating the electric potential and the spatial current density distribution in the brain due to transcranial stimulation using the method of fundamental solutions (MFS) has recently been proposed [209].

Horton et al. [210-212], Miller et al. [213, 214] and Zhang et al. [215] implemented an algorithm based on the EFG method, total Lagrangian explicit dynamics and geometrically nonlinear formulation, which they called a meshless total Lagrangian explicit dynamics (MTLED) algorithm. The MTLED algorithm was designed for use in real-time surgical simulation, the subject-specific biomechanical simulation of brain indentation, and brain image registration. The implementation steps and procedure for this approach are reproduced in Fig. 6. The validity of the algorithm was exemplified by a simplified 3D simulation of a craniotomy induced brain shift, including the brain, ventricles, tumor, subarachnoid space 
and skull, computation of the reaction force acting on a biopsy needle, and the indentation of brain tissue. Brain geometry was constructed from MRI images and discretized with nodes, while background cells were used for the numerical integration and explicit time integration was performed via the central difference method. The results obtained compared well with those obtained using LS-DYNA (commercial FEM software).

\begin{tabular}{|c|c|}
\hline & $\begin{array}{c}\text { MULA } \\
\text { Pro Procossling }\end{array}$ \\
\hline 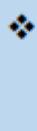 & $\begin{array}{l}\text { Discretize problem } \\
\text { geometry with meshfree } \\
\text { nodes. }\end{array}$ \\
\hline$*$ & $\begin{array}{l}\text { Generate integration } \\
\text { background cells. }\end{array}$ \\
\hline$*$ & $\begin{array}{l}\text { Define meshfree nodes } \\
\text { in the essential and } \\
\text { natural boundary. }\end{array}$ \\
\hline$\star$ & $\begin{array}{l}\text { Initialize material } \\
\text { properties. }\end{array}$ \\
\hline$*$ & $\begin{array}{l}\text { Loop through list of } \\
\text { integration points. For } \\
\text { each integration points: }\end{array}$ \\
\hline & $\begin{array}{l}\text { Define the support } \\
\text { domain containing } \\
N P \text { local nodes. }\end{array}$ \\
\hline & $\begin{array}{l}\text { Create and store the } \\
3 \times N P \text { matrix } D \Phi(\mathbf{x}) \text { of } \\
\text { MLS shape function } \\
\text { derivatives with } \\
\text { respect to the } \\
\text { reference } \\
\text { configuration. }\end{array}$ \\
\hline$*$ & $\begin{array}{l}\text { Loop through nodes and } \\
\text { associate with each node } \\
\text { a suitable mass. }\end{array}$ \\
\hline$*$ & $\begin{array}{l}\text { Initialize global nodal } \\
\text { displacements }{ }^{-\Delta t} \mathbf{U} \text { and } \\
{ }^{0} \mathbf{U} \text {. }\end{array}$ \\
\hline
\end{tabular}

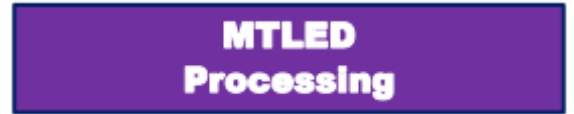

For every time step $t$ :

* Loop through list of integration points.

- From precomputed list, find NP local nodes and associate shape function derivatives $D \Phi(\mathbf{x})$ for the given integration points $\mathbf{X}$.

- Find $N P \times 3$ local nodal deformation matrix ${ }^{t} \mathbf{u}$.

- Calculate deformation gradient ${ }_{0}^{t} \mathbf{F}$.

- Calculate straindisplacement matrix ${ }_{0}^{t} \mathbf{B}_{L}$.

- Calculate second PiolaKirchhoff stress vector ${ }_{0}^{t} \hat{\mathbf{S}}$ using constitutive law.

- Calculate and store local nodal reaction forces ${ }_{0}^{t} f=\int_{V^{0}}{ }_{0}^{t} \mathbf{B}_{L}^{T}{ }_{0}^{t} \hat{\mathbf{S}} \mathrm{d} V^{0}$.

* Assemble the global nodal reaction forces vector ${ }_{0}^{t} \mathbf{R}$.

* Calculate global nodal displacements at time $t+\Delta t$ using central difference method

$$
\begin{array}{r}
{ }^{t+\Delta t} \mathbf{U}=-\Delta t^{2} \mathbf{M}^{-1}\left({ }_{0}^{t} \mathbf{R}-{ }^{t} \mathbf{P}\right)+ \\
2{ }^{t} \mathbf{U}-{ }^{t-\Delta t} \mathbf{U} .
\end{array}
$$

where $\mathbf{M}$ is the diagonal mass matrix and ${ }^{t} \mathbf{P}$ is the load applied at time $t$.

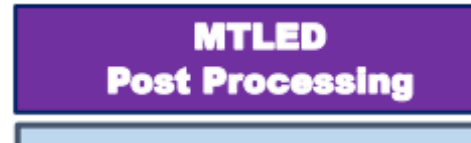

* Display meshfree nodes discretizing the problem domain.

* Visualize the distribution of integration points on the problem domain (optional).

* Visualize the displacement / deformation field.

* Visualize the stress field (optional).

Fig. 6 Summarized implementation procedure of the MTLED algorithm (modified [212]).

In a similar study, Berger et al. [216] coupled the FEM and meshfree methods for the modeling of brain deformation in response to tumor growth. Using the MTLED algorithm, Chowdhury et al. [217] implemented a modified moving least squares approximation for 
predicting soft tissue deformation using a regularized weight function with almost interpolating properties, and hence making the imposition of the essential boundary condition easier. The improved algorithm was used for the simulation of 2D brain deformation. In order to overcome the problems associated with brain atlas to patient registration in the presence of tumors, Diaz and Boulanger [218] proposed a novel method that brings closer the atlas and the patient's image by simulating the mechanical behavior of brain deformation under a tumor pressure. In their study, a meshfree total Lagrangian explicit dynamic (MTLED) algorithm was implemented to deal with the tumor mass-effect simulation, and a new tumor growth model for the simulation, which uses the shape of the segmented tumor from multimodal MRI data instead of assuming an unrealistic regular shape. In a more recent study, Marques et al. [219] presented a brain impact stress analysis using advanced discretization meshless techniques in which the realistic geometry of the brain was constructed from medical images.

\subsection{Arteries, Blood Flow and Transport in Capillaries}

It is a well-known and established fact that three-dimensional blood flow is governed by the Navier-Stokes (N-S) equations, together with the continuity equation, while mass transfer through the arterial wall and within the blood lumen, when coupled with the blood flow, can be modeled using the convection-diffusion equation. In this section, we review previous works where meshfree or particle methods have been employed to study artery related issues, such as atherosclerosis, blood flow and red blood cell (RBC) dynamics, and mass transportation in microcapillaries.

Tang and his colleagues [220] implemented MRI-based 2D and 3D models, coupled with multi-component plaque structure and fluid-structure interactions, to predict plaque progression and prevent potential rupture using the MLPG meshfree method. In their studies, blood flow was assumed to be laminar, Newtonian, viscous, and incompressible, the artery wall and plaque material were assumed to be hyperelastic, isotropic, incompressible and homogeneous while the NS equations with arbitrary Lagrangian-Eulerian (ALE) formulations were used as the governing equations. They concluded that plaque progression has a negative correlation with structural stress and flow shear stress conditions. Similar studies were also carried out using the meshless GFD method with and without fluid-structure interactions [221-223]. The authors also studied 3D viscous flow in stenotic tubes/arteries while incorporating the effect of large wall deformation and collapse [224], and the effect of 
stenosis asymmetry, on steady blood flow and artery compression using a 3D FSI interaction model by solving the governing models (the N-S equations and hyperelastic Mooney-Rivlin model), by means of the GFD method [225, 226].

More recently, Belinha et al. [227] implemented a 2D elastoplastic model to analyze the biomechanical behavior of atherosclerotic plaque tissue in an artery using the NNRPIM meshless method. Sinnott and his colleagues [228] studied how arterial pressures affect the consideration of internal carotid artery angle as a risk factor for the carotid atherosclerotic disease. This was achieved by using the SPH meshfree method to simulate Newtonian flow through clinical, rigid walled, carotid bifurcation, and it was observed that varying the angle without changing boundary pressure conditions produces minimal change in flow and wall shear stress (WSS). In addition, the importance of the internal carotid artery (ICA) in maintaining a well-behaved flow was identified.

El Zahab et al. [229] developed a localized collocation meshless method (LCMM) to model laminar incompressible blood flow in the interconnection between a bypass graft and an artery. Using the same method, coupled with the genetic algorithm, they further studied how blood flow in the synthetic bypass graft end-to-side distal anastomosis (ETSDA) can be improved by optimizing ETSDA shape [230, 231]. Tanaka and Takano [232] developed a microscopic blood model in which plasma fluid was discretized by SPH particles, and RBC was expressed by internal SPH particles surrounded by elastic membrane particles. To verify their model, they numerically analyzed two popular phenomena of blood flow: the tank-tread motion of an RBC under a constant shear field and the axial migration or pinch effect of RBCs in Poiseuille flow.

The authors in [233] proposed a physical meshless soft tissue model possessing viscoelastic creep characteristics and a range-based SPH method with variable smoothing length for simulation of blood flow effect in the virtual surgery training system. They also simulated kidney soft tissue cutting experiment using the proposed model and method. The results of their studies show significant improvement in the cutting and simulation effect in terms of the viscoelasticity of the soft tissue cutting and the pressure and viscous force of blood flow. Jichuan et al. [234] proposed a software component approach for GPU physics-based simulation of blood flow, internal fluidic structure and hand circulation by using an improved SPH method for the fluid dynamics of blood flow and an FE modeler for the interaction with arterial wall. Caballero et al. [235] investigated the capability of the SPH technique to simulate the bulk blood flow dynamics in two realistic left ventricular (LV) models. 
Tsubota et al. [236] studied the motion of RBCs in 2D blood flow using the MPS method. The cases considered in their study included the motion and deformation of a single RBC between parallel plates, primary thrombogenesis caused by platelet aggregation, and the collective behavior of multiple RBCs. Chui and Heng [237] also proposed a particle-based rheologic modeling method for virtual catheterization training applications. They simulated the effect of blood rheology through an SPH formulation of non-Newtonian flow, and a pure Lagrange particle formulation for fluid-structure interaction was proposed for the simulating of blood-vessel interaction by modeling the vessel wall structure as virtual particles. SPH has also been used to simulate how malaria parasites reduce the deformability of infected red blood cells [238] and to model the near-wall dynamics of leukocytes in flow [239]. Although the SPH approach has been widely employed for modeling blood flow, the difficulty of discretizing complex continuum geometries into pseudo-particles was recently overcome by mean of a multiblock approach [240] in which the whole problem domain is divided into simpler blocks, which are then discretized into evenly sized pseudo-particles.

The DPD particle method has been employed by various researchers and research group to investigate blood flow in circulation and devices [241-244] and RBC dynamics [245-252] as well as lipid bilayer-cytoskeleton [253]. Similar studies on blood flow, RBC dynamics and thrombus formulation have also been carried out using the SPH method [254-259], the modified particle binary level set (MPBLS) method [260], multi-particle collision (MPC) dynamics based on meshless membrane model [261] and the MPS method [262, 263]. Ariane et al. [264] propose a mesh-free and discrete (particle-based) multi-physics approach for modeling the hydrodynamics in flexible biological valves.

In a bid to further understand the rheology of RBC aggregation, Liu and Liu [265] introduced a new three-dimensional model that coupled NS equations with cell interactions to investigate RBC aggregation and its effect on blood rheology. In their studies, the RKPM meshfree technique was used to model the RBCs in order to overcome the challenges associated with the large deformation of RBCs. The efficiency of their model was validated with studies on the peeling force of an RBC rouleau, the effects of shear-rate dependent viscosity on cell aggregation, the effect of RBC deformability on blood viscosity and the Fahraeus-Lindqvist effect. More recently, Ghehsareh et al. [266] presented numerical solutions of a mathematical model of blood flow in the deforming (expanding and contracting) porous channel using the integration radial basis function collocation method. 


\subsection{Cell mechanics}

Cellular systems, which are also referred to as nature's building blocks, are one of the most studied systems since these unique microscopic units control the overall macroscopic behavior of both animals and plants. From a biomechanics point of view, plant cells are intuitively slightly simpler than animal cells due to their high degree of immobility within the organism. In this section, we present a summary of some key studies and investigations in the literature relating to cell mechanics, in which meshfree or/and particle methods are employed.

In [267], Van Liedekerke and his colleagues employed the SPH method to simulate and study the micromechanics of single-plant parenchyma cells and aggregates. The micromechanics of biological cells was investigated by the same authors [268] through the coupling of SPH (to model the cell fluid) with the discrete element method (DSEM), in order to model the viscoelastic cell wall as an isotropic incompressible neo-Hookean solid. In their studies, cell wall hydraulic conductivity (permeability) was built in through a constitutive relation in the SPH formulation, the force transmission and stresses in the biological parenchyma cells were predicted and the mechanics (both during and after cell failure) was also modeled.

Following the works of Van Liedekerke, Karunasena and his co-workers [269, 270] simulated the microscale large deformation behavior of different plant food materials and plant cell shrinkage during drying using a coupled SPH-DSEM approach. To predict various macroscopic properties in the transverse plane of wood - namely, spruce earlywood, spruce latewood and poplar - a combination of three approaches was used by Perré and his colleagues [271]. In their study, the authors implemented the lattice Boltzmann method (LBM), MPM and peridynamic approaches to predict thermal conductivity and mass diffusivity, compute rigidity and compression at large deformation, and predict the fracture pathway in the cellular arrangement, respectively.

Nakamura et al. [272] analyzed RBC deformation behavior in various flow fields, such as the Couette flow, unsteady shear flows and stenosed flows, so as to determine whether the extent of RBC deformation given by a deformation index can be correlated with the external fluid shear stress, by implementing a spring-based model and solving the motion equation defined for each node with a given mass. The mechanics of platelet aggregation in hemodynamic flows was modeled using a combination of the immersed boundary method and parametric radial basis function (IB-RBF) by tracking the motion and behavior of a collection of 
individual platelets as they interacted with the suspending fluid, one another and the vessel walls [273].

Liew and his co-workers employed an atomistic-continuum model to study the elastic properties, buckling and post-buckling, vibration and dynamic behaviors of microtubules [274-278]. Wang et al. [279, 280] also implemented a nanoscale quasi-continuum (QC) model for exploring the mechanical behaviors of human erythrocyte membranes using the higher order Cauchy-Born rule and meshfree method. A 3D multiscale Cauchy-Born meshfree model was proposed by Ademiloye and co-workers [281, 282] as an improvement to the 2D QC model employed in [279, 280, 283] for numerical modeling of the deformability of RBC membrane parasitized by Plasmodium falciparum. This methodology and its semi-analytical variant has been employed to examined the large deformation behavior [284, 285] of healthy RBC membrane, biomechanical properties of malaria-infected RBC membrane [286] as well as the effects of thermal treatments on healthy RBC membrane deformability [287] and its biomechanical responses under various loading conditions [288, 289].

Zeng and his co-workers [290-292] developed a multiscale soft matter model as a generalization of the Fluid Mosaic Model [293], and as an extension of Helfrich's membrane model [294] for stem cells, in order to model soft contact and adhesion between cells and their extracellular substrates using a Lagrange-type meshfree Galerkin formulation. To validate the proposed model, the response of cells in four different stiffness substrates and in a stiffness-varying substrate, as well as conformation change due to substrate elasticity and three-dimensional (3D) cell spreading, were investigated. More recently, Pothapragada et al. [295] developed a phenomenological 3D coarse-grained molecular dynamics (CGMD) particle-based platelet model to describe the filopodia formation and imitate the complex shape change observed during early stage platelet activation. Heck et al. [296] proposed a viscoelastic SPH technique with extended boundary conditions for numerical modeling of extracellular matrix in contact with a migrating cell.

\subsection{Human Swimming Locomotion and Bird Flights}

Cohen and his colleagues employed the SPH method to perform numerical simulations of dolphin kick [297] and fixed glide pose towing [298] swimming drills. The authors also studied the locomotion of marine animals such as dolphins and sharks [299], the pitching effects of buoyancy during free-style, backstroke, butterfly and breaststroke swimming 
techniques [300], the role of hand during freestyle swimming drill [301], as well as the prediction of loading on the body during elite platform diving [302]. In their pioneering work, McCarthy et al. [303] investigated the impact of a bird on an aircraft wing leading edge structure using the PAM-CRASH software. They showed that the SPH technique was able to capture the breakup of the bird into debris particle after the collision.

In a similar study, Guida et al. [304] employed an SPH-Lagrangian approach to study the impact of bird-strike on the leading edge wing of aircraft by modeling the bird geometry with SPH nodes and the impacted structure using Lagrangian elements. The authors further investigated the impact, failure after impact and high strength at impact properties of glass fibre laminate combination sandwich composite. However, the bird geometry (i.e. hemispherical-ended cylinder) used for their simulations [303, 304] is unrealistic.

Grimaldi et al. [305] presented a study on aircraft windshield-surround structure with an innovative configuration that satisfies the bird-strike requirement according to the European and US aviation regulations 25.631 on the "Bird-strike Damage" using a coupled FE-SPH approach. In addition, the authors presented a parametric analysis on the square windshield model to investigate the effect of the target geometry, the impact angle, and the plate curvature on the impact response of the windshield structure with the aim of defining possible guidelines for the design of a bird-proof airplane windshield. The effects of using realistic and substitute bird models as well as the influence of bird geometry on aircraft impacts from various orientations were studied by Hedayati and Ziaei-Rad [306]. The authors concluded that impact from bird bottom side is the most damaging scenario, while the tail side impact is the less dangerous one.

Vignjevic et al. [307] employed the particle to node and the particle to surface contact algorithms for the treatment of contact between the bird, modeled using SPH particles and the aircraft blade (modeled as FE mesh) in a bird-strike analysis. The influence of bird shape, bird impact location and impact timing were then investigated in their parametric study. It has also been reported in the open literature that during bird strikes, the geometry configuration of bird severely affects the displacement and the von Mises stress of some rotary engine primary compressor blades and if the bird strikes the "up" sites, some blades may develop plastic deformation which will adversely affect the safety work of the engine [308].

Jun et al. [309] studied the dynamic plastic responses of the sidewall structure of an aircraft nose using the coupled SPH-FE method in PAM-CRASH software. Zhang and Fei [310] 
employed the SPH method to investigate the effect of bird geometry and impact orientation in bird striking on a rotary jet-engine fan. The authors implemented a more realistic bird model in terms of bird geometry and material constitutive model. They concluded that bird geometry and impact orientation had a significant effect on the impact force, impact duration and kinetic energy loss of the bird.

\subsection{Other Applications}

The use of a point-cloud method (a form of meshfree method based on the nodal discretization of a problem domain) for image-based stress analysis in biological systems, such as aorta inflation and skull impact, was demonstrated by Qian and Lu [311]. A 3D material point human head model constructed from CT scanned images was used to study the dynamic response of the human head under the impact of a 3D cylindrical lead projectile [312], while the penetration of projectile into the human head was studied using SPH method [313]. Recently, a discrete particle-based method capable of representing the entire boiling process, including nucleation, bubble formation, growth, bursting, vapor and steam formation at the fluid-free surface was proposed using the meshfree SPH method [314].

Huafeng and Liu [315] applied the EFG method to several image analysis problems involving domain evolution and domain mapping, such as object segmentation and multi-frame cardiac motion analysis. Chen et al. [316, 317] proposed a 3D object-constrained meshless deformable algorithm for prostrate segmentation and registration in image-guided radiotherapy (IGRT) using $\mathrm{CT}$, on board cone beam $\mathrm{CT}$ images and certain recent dose delivery technologies, such as intensity modulated radiation therapy (IMRT). A coupled RBF interpolation and statistical shape model were used to establish a comparison between ultrasound (US) and magnetic resonance (MR) based 3D prostate shapes [318]. In this study, the authors first used RBF interpolation to construct a 3D point distribution model for each prostate, before a modified principal axis transformation was utilized for the rigid registration of the US and MR images of the same prostate in preparation for shape comparison. Lastly, statistical shape models were used to capture the segmented 3D prostate geometries for successive cross-modality comparison.

A point-based simulation and cutting of herniated disc soft-tissue in the context of interactive surgery simulation was implemented by Haq and his co-workers [319] using the MLS approximation scheme. In their study, an intrinsic meshless distance-based enrichment technique capable of handling discontinuities was implemented to perform the cutting 
operation smoothly. Using the MTLED algorithm, combined with fuzzy tissue classification (which relies on the Fuzzy C-Means algorithm to compute and assign material properties using fuzzy membership functions for the specified image intensity clusters for each voxel in the image), Li et al. [320, 321] presented a patient-specific meshless model for whole-body image registration. An et al. [322], in their recent article, proposed a meshless reconstruction method capable of reducing position error, for fluorescence molecular tomography (FMT), based on the compactly supported radial basis function.

By combining RBFs with partial differential equation-based nonlinear level set evolution equation, $\mathrm{Li}$ and $\mathrm{Li}$ [323] presented a meshless numerical algorithm for image segmentation that is robust to initialization and more computationally efficient. Aggarwal et al. [324] recently proposed an RKPM meshfree method for large deformation mechanics of protein structure by studying the mechanics and conformational change of proteins and their assemblies. The authors simulated the atomic force microscopy (AFM) indentation of cowpea chlorotic mottle virus (CCMV) native capsid by defining meshfree nodes at the $\alpha$-carbon positions of the atomic coordinates and analyzed the conformational change of protein assemblies and discussed the importance of coarse-graining methods. A local meshless collocation method for solving the partial differential equations arising from modeling of wound healing processes was presented by the authors in [325].

A degenerate parabolic equation arising in the spatial diffusion of the biological population has also been analyzed using the element free $k p$-Ritz method [326] and IMLS-Ritz meshfree method [20]. The authors in [327] investigated the relationships between peristaltic contraction, relaxation, and fluid transport in the human colon using the SPH method, by coupling the flow of luminal content and wall flexure. Recently, Montanino et al. [328] presented a meshfree approach for modeling the cornea-aqueous humor interaction during air puff test. Dehghan and co-workers [329, 330] simulated the behavior of cancer cell invasion of surrounding tissue as well as the process of tumor growth using meshless techniques. Fu et al. [331] proposed a domain-type meshless collocation method, called method of approximate particular solutions (MAPS), for numerical investigation on the effect of tumor on the thermal behavior inside the skin tissue. The Galerkin-based meshfree method has also been employed by the authors in $[332,333]$ for numerical simulation of reaction-diffusion systems in developmental biology, which is one of the emerging areas of interest in computational biomechanics. 


\section{Concluding Remarks and Prospects}

This review aims to assist researchers working with meshfree and particle methods within the fields of bioengineering and computational biomechanics by providing them with the key references for use in their research, as well as ideas for future research areas considered to be of paramount importance. The above-mentioned aims were achieved with the comprehensive review of applications of meshfree and particle methods in bioengineering and biomechanics. We made an extensive effort to include all the important contributions in the current areas of interest highlighting the most pertinent literature available to researchers studying and working in the field of computational biomechanics.

We observed that the meshfree and particle methods have been widely employed for various problems in computational biomechanics; however, the use of conventional meshfree methods such as EFG, RKPM and MLPG in biofluid mechanics and FSI related studies is limited. The superior performance of these methods in handling problems involving large deformation and complex geometry without loss of accuracy can be harnessed to investigate and solve important problems in emerging areas in computational biomechanics. These emerging areas and areas with significant research opportunities include fetal and neonatal skeletal development, tumor growth and cancer metastasis, brain concussion and morphogenesis, intrathecal cerebrospinal fluid dynamics, multiscale biomechanics, in silico regenerative mechanics, data-driven modeling, rupture mechanics, 3D printing and mechanics of medical devices.

Considering the enormous advantages of meshfree and particle methods, coupled with the constantly increasing interest in bioengineering and biomechanics, we are confident that this fascinating and potentially useful area of research will continue to aid in the improvement of human health through its novel and insightful contribution to the world of science and technology.

\section{References}

1. Kojić M, Filipović N, Stojanović B, Kojić N (2008) Computer modeling in bioengineering: Theoretical background, examples and software. John Wiley \& Sons, Chichester, England; Hoboken, NJ

2. Lucy L (1977) A numerical approach to the testing of the fission hypothesis. Astron J 82:1013-1024.

3. Monaghan J (1982) Why particle methods work. SIAM J Sci Stat Comput 3:422-433. doi: $10.1137 / 0903027$ 
4. Monaghan J (1988) An introduction to SPH. Comput Phys Commun 48:89-96. doi: 10.1016/00104655(88)90026-4

5. Stellingwerf RF, Wingate CA (1993) Impact modeling with smooth particle hydrodynamics. Int J Impact Eng 14:707-718. doi: 10.1016/0734-743X(93)90065-F

6. Libersky LD, Petschek AG (1991) Smooth particle hydrodynamics with strength of materials. In: Trease H, Fritts M, Crowley WP (eds) Advances in the Free-Lagrange Method Including Contributions on Adaptive Gridding and the Smooth Particle Hydrodynamics Method SE - 26. Springer Berlin Heidelberg, pp 248-257

7. Nayroles B, Touzot G, Villon P (1992) Generalizing the finite element method: Diffuse approximation and diffuse elements. Comput Mech 10:307-318. doi: 10.1007/BF00364252

8. Lancaster P, Salkauskas K (1981) Surface generated by moving least square methods. Math Comput 37:141-158. doi: 10.1090/S0025-5718-1981-0616367-1

9. Belytschko T, Lu YY, Gu L (1994) Element-free Galerkin methods. Int J Numer Methods Eng 37:229256. doi: 10.1002/nme.1620370205

10. Belytschko T, Gu L, Lu YY (1994) Fracture and crack growth by element-free Galerkin methods. Model Simul Mater Sci Eng 2:519-534. doi: 10.1088/0965-0393/2/3A/007

11. Belytschko T, Lu Y, Gu L, Tabbara M (1995) Element-free galerkin methods for static and dynamic fracture. Int J Solids Struct 32:2547-2570. doi: 10.1016/0020-7683(94)00282-2

12. Belytschko T, Lu Y, Gu L (1995) Crack propagation by element-free Galerkin methods. Eng Fract Mech 51:295-315. doi: 10.1016/0013-7944(94)00153-9

13. Cordes L, Moran B (1996) Treatment of material discontinuity in the Element-Free Galerkin method. Comput Methods Appl Mech Eng 139:75-89. doi: 10.1016/S0045-7825(96)01080-8

14. Krysl P, Belytschko T (1996) Analysis of thin shells by the Element-Free Galerkin method. Int J Solids Struct 33:3057-3080. doi: 10.1016/0020-7683(95)00265-0

15. Krysl P, Belytschko T (1995) Analysis of thin plates by the element-free Galerkin method. Comput Mech 17:26-35. doi: 10.1007/BF00356476

16. Zhang Z, Liew KM, Cheng Y (2008) Coupling of the improved element-free Galerkin and boundary element methods for two-dimensional elasticity problems. Eng Anal Bound Elem 32:100-107. doi: 10.1016/j.enganabound.2007.06.006

17. Zhang Z, Liew KM, Cheng Y, Lee YY (2008) Analyzing 2D fracture problems with the improved element-free Galerkin method. Eng Anal Bound Elem 32:241-250. doi: 10.1016/j.enganabound.2007.08.012

18. Zhang Z, Zhao P, Liew KM (2009) Improved element-free Galerkin method for two-dimensional potential problems. Eng Anal Bound Elem 33:547-554. doi: 10.1016/j.enganabound.2008.08.004

19. Zhang Z, Zhao P, Liew KM (2009) Analyzing three-dimensional potential problems with the improved 
element-free Galerkin method. Comput Mech 44:273-284. doi: 10.1007/s00466-009-0364-9

20. Zhang LW, Deng YJ, Liew KM (2014) An improved element-free Galerkin method for numerical modeling of the biological population problems. Eng Anal Bound Elem 40:181-188. doi: 10.1016/j.enganabound.2013.12.008

21. Zhang Z, Hao SY, Liew KM, Cheng YM (2013) The improved element-free Galerkin method for twodimensional elastodynamics problems. Eng Anal Bound Elem 37:1576-1584. doi: 10.1016/j.enganabound.2013.08.017

22. Atluri SN, Zhu T (1998) A new meshless local Petrov-Galerkin (MLPG) approach in computational mechanics. Comput Mech 22:117-127. doi: 10.1007/s004660050346

23. Zhu T, Zhang J-D, Atluri SN (1998) A local boundary integral equation (LBIE) method in computational mechanics, and a meshless discretization approach. Comput Mech 21:223-235. doi: $10.1007 / \mathrm{s} 004660050297$

24. Mirzaei D (2015) A new low-cost meshfree method for two and three dimensional problems in elasticity. Appl Math Model 39:7181-7196. doi: 10.1016/j.apm.2015.02.050

25. Mirzaei D, Schaback R (2013) Direct meshless local Petrov-Galerkin (DMLPG) method: A generalized MLS approximation. Appl Numer Math 68:73-82. doi: 10.1007/s11075-013-9711-1

26. Liew KM, Huang YQ, Reddy JN (2003) Moving least squares differential quadrature method and its application to the analysis of shear deformable plates. Int J Numer Methods Eng 56:2331-2351. doi: $10.1002 /$ nme. 646

27. Liew KM, Huang YQ, Reddy JN (2003) Vibration analysis of symmetrically laminated plates based on FSDT using the moving least squares differential quadrature method. Comput Methods Appl Mech Eng 192:2203-2222. doi: 10.1016/S0045-7825(03)00238-X

28. Liu W, Jun S, Zhang Y (1995) Reproducing kernel particle methods. Int J Numer Methods Fluids 20:1081-1106. doi: 10.1002/fld.1650200824

29. Liu W, Li S, Belytschko T (1997) Moving least-square reproducing kernel methods (I): methodology and convergence. Comput Methods Appl Mech Eng 143:113-154. doi: 10.1016/S0045-7825(96)011322

30. Chen J-S, Wu C-T, Yoon S, You Y (2001) A stabilized conforming nodal integration for Galerkin mesh-free methods. Int J Numer Methods Eng 50:435-466. doi: 10.1002/10970207(20010120)50:2<435::AID-NME32>3.0.CO;2-A

31. Chen J-S, Pan C, Wu C-T, Liu WK (1996) Reproducing Kernel Particle Methods for large deformation analysis of non-linear structures. Comput Methods Appl Mech Eng 139:195-227. doi: 10.1016/S00457825(96)01083-3

32. Chen J-S, Pan C, Roque CMOL, Wang H-P (1998) A Lagrangian reproducing kernel particle method for metal forming analysis. Comput Mech 22:289-307. doi: 10.1007/s004660050361 
33. Chen J-S, Pan C, Wu C-T (1997) Large deformation analysis of rubber based on a reproducing kernel particle method. Comput Mech 19:211-227. doi: 10.1007/s004660050170

34. Liew KM, Wu HY, Ng TY (2002) Meshless method for modeling of human proximal femur: treatment of nonconvex boundaries and stress analysis. Comput Mech 28:390-400. doi: 10.1007/s00466-0020303-5

35. Liew KM, Ng TY, Wu YC (2002) Meshfree method for large deformation analysis-a reproducing kernel particle approach. Eng Struct 24:543-551. doi: 10.1016/S0141-0296(01)00120-1

36. Liew KM, Ng TY, Zhao X, Reddy JN (2002) Harmonic reproducing kernel particle method for free vibration analysis of rotating cylindrical shells. Comput Methods Appl Mech Eng 191:4141-4157. doi: $10.1016 / \mathrm{S} 0045-7825(02) 00358-4$

37. Wang J, Liew KM, Tan MJ, Rajendran S (2002) Analysis of rectangular laminated composite plates via FSDT meshless method. Int J Mech Sci 44:1275-1293. doi: 10.1016/S0020-7403(02)00057-7

38. Cheng R, Liew KM (2009) The reproducing kernel particle method for two-dimensional unsteady heat conduction problems. Comput Mech 45:1-10. doi: 10.1007/s00466-009-0401-8

39. Zhao X, Liew KM, Ng TY (2003) Vibration analysis of laminated composite cylindrical panels via a meshfree approach. Int J Solids Struct 40:161-180. doi: 10.1016/S0020-7683(02)00475-4

40. Sulsky D, Zhou S, Schreyer H (1995) Application of a particle-in-cell method to solid mechanics. Comput Phys Commun 87:236-252. doi: 10.1016/0010-4655(94)00170-7

41. Sulsky D, Schreyer H (1996) Axisymmetric form of the material point method with applications to upsetting and Taylor impact problems. Comput Methods Appl Mech Eng 139:409-429. doi: 10.1016/S0045-7825(96)01091-2

42. Melenk J, Babuška I (1996) The partition of unity finite element method: basic theory and applications. Comput Methods Appl Mech Eng 139:289-314. doi: 10.1016/S0045-7825(96)01087-0

43. Oñate E, Idelsohn S, Zienkiewicz OC, et al (1996) A stabilized finite point method for analysis of fluid mechanics problems. Comput Methods Appl Mech Eng 139:315-346. doi: 10.1016/S00457825(96)01088-2

44. Oñate E, Idelsohn S, Zienkiewicz OC, Taylor RL (1996) A finite point method in computational mechanics. Applications to convective transport and fluid flow. Int J Numer Methods Eng 39:38393866. doi: 10.1002/(SICI)1097-0207(19961130)39:22<3839::AID-NME27>3.0.CO;2-R

45. Oñate E, Perazzo F, Miquel J (2001) A finite point method for elasticity problems. Comput Struct 79:2151-2163. doi: 10.1016/S0045-7949(01)00067-0

46. Kansa EJ (1990) Multiquadrics - A scattered data approximation scheme with applications to computational fluid-dynamics - I surface approximations and partial derivative estimates. Comput Math with Appl 19:127-145. doi: 10.1016/0898-1221(90)90270-T

47. Kansa EJ (1990) Multiquadrics-A scattered data approximation scheme with applications to 
computational fluid-dynamics-II solutions to parabolic, hyperbolic and elliptic partial differential equations. Comput Math with Appl 19:147-161. doi: 10.1016/0898-1221(90)90271-K

48. Hardy RL (1990) Theory and applications of the multiquadric-biharmonic method (20 years of discovery 1968-1988). Comput Math with Appl 19:163-208. doi: 10.1016/0898-1221(90)90272-L

49. Ferreira AJM (2003) A formulation of the multiquadric radial basis function method for the analysis of laminated composite plates. Compos Struct 59:385-392. doi: 10.1016/S0263-8223(02)00239-8

50. Ferreira AJM, Roque CMC, Martins PALS (2004) Radial basis functions and higher-order shear deformation theories in the analysis of laminated composite beams and plates. Compos Struct 66:287293. doi: 10.1016/j.compstruct.2004.04.050

51. Ferreira AJM, Roque CMC, Jorge RMN (2005) Free vibration analysis of symmetric laminated composite plates by FSDT and radial basis functions. Comput Methods Appl Mech Eng 194:42654278. doi: 10.1016/j.cma.2004.11.004

52. Liu GR, Gu YT (2001) A point interpolation method for two-dimensional solids. Int J Numer Methods Eng 50:937-951. doi: 10.1002/1097-0207(20010210)50:4<937::AID-NME62>3.0.CO;2-X

53. Liu GR, Dai KY, Lim KM, Gu YT (2002) A point interpolation mesh free method for static and frequency analysis of two-dimensional piezoelectric structures. Comput Mech 29:510-519. doi: $10.1007 / \mathrm{s} 00466-002-0360-9$

54. Liu GR, Zhang GY, Gu YT, Wang YY (2005) A meshfree radial point interpolation method (RPIM) for three-dimensional solids. Comput Mech 36:421-430. doi: 10.1007/s00466-005-0657-6

55. Cui X, Liu G, Li G (2011) A smoothed Hermite radial point interpolation method for thin plate analysis. Arch Appl Mech 81:1-18. doi: 10.1007/s00419-009-0392-0

56. Sukumar N, Belytschko T (1998) The natural element method in solid mechanics. Int J Numer Methods Eng 43:839-887. doi: 10.1002/(SICI)1097-0207(19981115)43:5<839::AID-NME423>3.0.CO;2-R

57. Sukumar N, Moran B, Yu Semenov A, Belikov VV (2001) Natural neighbour Galerkin methods. Int J Numer Methods Eng 50:1-27. doi: 10.1002/1097-0207(20010110)50:1<1::AID-NME14>3.0.CO;2-P

58. Voronoi GM (1908) Nouvelles applications des paramètres continus à la théorie des formes quadratiques. Deuxième Mémoire: Recherches sur les paralléloèdres primitifs. J für die reine und Angew Math 134:198-287. doi: 10.1515/crll.1909.136.67

59. Delaunay B (1934) Sur la sphére vide. A la mémoire de Georges Voronoi. Bull l'académie des Sci l'URSS Cl des Sci mathématiques na 793-800.

60. Dinis LMJS, Jorge RMN, Belinha J (2009) The natural neighbour radial point interpolation method: dynamic applications. Eng Comput 26:911-949. doi: 10.1108/02644400910996835

61. Sukumar N (2004) Construction of polygonal interpolants: A maximum entropy approach. Int J Numer Methods Eng 61:2159-2181. doi: 10.1002/nme.1193

62. Ortiz A, Puso MA, Sukumar N (2010) Maximum-entropy meshfree method for compressible and near- 
incompressible elasticity. Comput Methods Appl Mech Eng 199:1859-1871. doi: 10.1016/j.cma.2010.02.013

63. Arroyo M, Ortiz M (2006) Local maximum-entropy approximation schemes: A seamless bridge between finite elements and meshfree methods. Int J Numer Methods Eng 65:2167-2202. doi: $10.1002 / \mathrm{nme} .1534$

64. González D, Cueto E, Doblaré M (2010) A higher order method based on local maximum entropy approximation. Int J Numer Methods Eng 83:741-764. doi: 10.1002/nme.2855

65. Liu GR (2001) A point assembly method for stress analysis for two-dimensional solids. Int J Solids Struct 39:261-276. doi: 10.1016/S0020-7683(01)00172-X

66. Idelsohn SR, Oñate E, Calvo N, Del Pin F (2003) The meshless finite element method. Int J Numer Methods Eng 58:893-912. doi: 10.1002/nme.798

67. Belinha J, Dinis LMJS, Jorge RMN (2013) The natural radial element method. Int J Numer Methods Eng 93:1286-1313. doi: 10.1002/nme.4427

68. Cundall PA (1971) A computer model for simulating progressive large scale movements in blocky rock systems. In: Proceedings of the International Symposium on Rock Mechanics. Nancy, France

69. Hoogerbrugge PJ, Koelman JMVA (2007) Simulating microscopic hydrodynamic phenomena with dissipative particle dynamics. Europhys Lett 19:155-160. doi: 10.1209/0295-5075/19/3/001

70. Koshizuka S, Oka Y (1996) Moving-particle semi-implicit method for fragmentation of incompressible fluid. Nucl. Sci. Eng. 123:421-434

71. Liszka T, Orkisz J (1980) The finite difference method at arbitrary irregular grids and its application in applied mechanics. Comput Struct 11:83-95. doi: 10.1016/0045-7949(80)90149-2

72. Dolbow J, Belytschko T (1998) An introduction to programming the meshless element free Galerkin method. Arch Comput Methods Eng 5:207-241. doi: 10.1007/BF02897874

73. Nguyen VP, Rabczuk T, Bordas S, Duflot M (2008) Meshless methods: A review and computer implementation aspects. Math Comput Simul 79:763-813. doi: 10.1016/j.matcom.2008.01.003

74. Liu GR, Gu YT (2005) An introduction to meshfree methods and their programming, 1st ed. Springer Science \& Business Media

75. Li S, Liu WK (2002) Meshfree and particle methods and their applications. Appl Mech Rev 55:1. doi: $10.1115 / 1.1431547$

76. De S, Kim J, Srinivasan M (2001) A meshless numerical technique for physically based real time medical simulations. Stud Health Technol Inform 113-118.

77. De S, Kim J, Lim YJ, Srinivasan MA (2005) The point collocation-based method of finite spheres (PCMFS) for real time surgery simulation. Comput Struct 83:1515-1525. doi: 10.1016/j.compstruc.2004.12.003

78. Zhu B, Gu L, Peng X, Zhou Z (2010) A point-based simulation framework for minimally invasive 
surgery. In: Bello F, Cotin S (eds) Biomedical Simulation. Springer Berlin Heidelberg, pp 130-138

79. Guilkey JE, Hoying JB, Weiss JA (2006) Computational modeling of multicellular constructs with the material point method. J Biomech 39:2074-2086. doi: 10.1016/j.jbiomech.2005.06.017

80. Ionescu I, Guilkey JE, Berzins M, et al (2006) Simulation of soft tissue failure using the material point method. J Biomech Eng 128:917-924. doi: 10.1115/1.2372490

81. Liu HT, Jiang S, Chen Z, et al (2015) Simulation of hard-soft material interaction under impact loading employing the material point method. Sci China Technol Sci 58:763-768. doi: 10.1007/s11431-0155780-9

82. Lim YJ, De S (2007) Real time simulation of nonlinear tissue response in virtual surgery using the point collocation-based method of finite spheres. Comput Methods Appl Mech Eng 196:3011-3024. doi: 10.1016/j.cma.2006.05.015

83. De S, Lim Y-J (2010) Interactive surgical simulation using a meshfree computational method. In: De S, Guilak F, Mofrad MRK (eds) Computational Modeling in Biomechanics. Springer Science+Business Media, LLC, New York, pp 1-581

84. Xu J, Wang L, Wong KCL, Shi P (2010) A meshless framework for bevel-tip flexible needle insertion through soft tissue. 2010 3rd IEEE RAS EMBS Int Conf Biomed Robot Biomechatronics, BioRob 2010 753-758. doi: 10.1109/BIOROB.2010.5625943

85. Zhu B, Gu L, Zhou Z (2010) Particle-based deformable modeling with pre-computed surface data in real-time surgical simulation. In: International Workshop on Medical Imaging and Virtual Reality. Springer Berlin Heidelberg, pp 503-512

86. Hieber SE, Walther JH, Koumoutsakos P (2004) Remeshed smoothed particle hydrodynamics simulation of the mechanical behavior of human organs. Technol Heal Care 12:305-314.

87. Banihani S, Rabczuk T, Almomani T (2013) POD for real-time simulation of hyperelastic soft biological tissue using the point collocation method of finite Spheres. Math Probl Eng 2013:1-9. doi: $10.1155 / 2013 / 386501$

88. Bao Y, Wu D, Yan Z, Du Z (2013) A new hybrid viscoelastic soft tissue model based on meshless method for haptic surgical simulation. Open Biomed Eng J 7:116-124. doi: $10.2174 / 1874120701307010116$

89. Liu X, Wang R, Li Y, Song D (2015) Deformation of Soft Tissue and Force Feedback Using the Smoothed Particle Hydrodynamics. Comput Math Methods Med 1-10. doi: 10.1155/2015/598415

90. Jin X, Joldes GR, Miller K, et al (2012) Meshless algorithm for soft tissue cutting in surgical simulation. Comput Methods Biomech Biomed Engin 17:800-811. doi: 10.1080/10255842.2012.716829

91. Jin X, Joldes GR, Miller K, Wittek A (2013) 3D Algorithm for Simulation of Soft Tissue Cutting. In: Wittek A, Miller K, Nielsen PMF (eds) Computational Biomechanics for Medicine. Springer New York, New York, NY, pp 49-62 
92. Abdi E, Farahmand F, Durali M (2012) A meshless EFG-based algorithm for 3D deformable modeling of soft tissue in real-time. Stud Health Technol Inform 173:1-7.

93. Cao L, Qin QH, Zhao N (2010) An RBF-MFS model for analysing thermal behaviour of skin tissues. Int J Heat Mass Transf 53:1298-1307. doi: 10.1016/j.ijheatmasstransfer.2009.12.036

94. Tao J, Qin QH, Cao L (2013) A Combination of Laplace Transform and Meshless Method for Analysing Thermal Behaviour of Skin Tissues. Univers J Mech Eng 1:32-42. doi: 10.13189/ujme.2013.010202

95. Zhang Z-W, Wang H, Qin Q-H (2014) Method of Fundamental Solutions for Nonlinear Skin Bioheat Model. J Mech Med Biol 14:1450060. doi: 10.1142/S0219519414500602

96. Zhang Z-W, Wang H, Qin Q-H (2015) Meshless method with operator splitting technique for transient nonlinear bioheat transfer in two-dimensional skin tissues. Int $\mathbf{J}$ Mol Sci 16:2001-2019. doi: 10.3390/ijms16012001

97. Jamil M, Ng EYK (2013) Evaluation of meshless radial basis collocation method (RBCM) for heterogeneous conduction and simulation of temperature inside the biological tissues. Int J Therm Sci 68:42-52. doi: 10.1016/j.ijthermalsci.2013.01.007

98. Bourantas GC, Loukopoulos VC, Burganos VN, Nikiforidis GC (2014) A meshless point collocation treatment of transient bioheat problems. Int J Numer Method Biomed Eng 30:587-601. doi: $10.1002 / \mathrm{cnm} .2626$

99. Bourantas GC, Ghommem M, Kagadis GC, et al (2014) Real-time tumor ablation simulation based on the dynamic mode decomposition method. Med Phys 41:053301. doi: 10.1118/1.4870976

100. Ghazanfarian J, Saghatchi R, Patil DV (2015) Implementation of smoothed-particle hydrodynamics for non-linear Pennes' bioheat transfer equation. Appl Math Comput 259:21-31. doi: 10.1016/j.amc.2015.02.036

101. Erhart K, Divo E, Kassab A (2008) An evolutionary-based inverse approach for the identification of non-linear heat generation rates in living tissues using a localized meshless method. Int $\mathrm{J}$ Numer Methods Heat Fluid Flow 18:401-414. doi: 10.1108/09615530810853655

102. Alford JB, Simkins DC, Rembert RA, Hoyte L (2014) Patient-specific modeling in urogynecology: A meshfree approach. Comput Model Eng Sci 98:129-149. doi: 10.3970/cmes.2014.098.129

103. Soon Hyoung Pyo, Jeongjin Lee, Seongjin Park, et al (2013) Physically Based Nonrigid Registration Using Smoothed Particle Hydrodynamics: Application to Hepatic Metastasis Volume-Preserving Registration. IEEE Trans Biomed Eng 60:2530-2540. doi: 10.1109/TBME.2013.2257172

104. Naeeni HA, Haghpanahi M (2012) Digital imaging validation of soft tissue phantom deformation via meshfree method. In: 2012 International Conference on Biomedical Engineering and Biotechnology. pp $777-780$

105. Wachowiak MP, Xiaogang Wang, Fenster A, Peters TM (2004) Compact support radial basis functions for soft tissue deformation. In: 2004 2nd IEEE International Symposium on Biomedical Imaging: Macro 
to Nano. IEEE, pp 1259-1262

106. Hao A, Huang Z (2011) A physical based meshless method for soft tissue deforming. Proc 2011 IEEE Int Symp IT Med Educ (ITME 2011) 2:293-296. doi: 10.1109/ITiME.2011.6132042

107. An Y, Liu J, Zhang G, et al (2016) Compactly supported radial basis function-based meshless method for photon propagation model of fluorescence molecular tomography. IEEE Trans Med Imaging 0062:1-1. doi: 10.1109/TMI.2016.2601311

108. Morais P, Queirós S, Ferreira A, et al (2016) Dense motion field estimation from myocardial boundary displacements. Int J Numer Method Biomed Eng 32:e02758. doi: 10.1002/cnm.2758

109. Zhou J, Luo Z, Li C, Deng M (2018) Real-time deformation of human soft tissues: A radial basis meshless 3D model based on Marquardt's algorithm. Comput Methods Programs Biomed 153:237-252. doi: 10.1016/j.cmpb.2017.09.008

110. Taddei L, Goumtcha AA, Roth S (2015) Smoothed particle hydrodynamics formulation for penetrating impacts on ballistic gelatine. Mech Res Commun 70:94-101. doi: 10.1016/j.mechrescom.2015.09.010

111. Nooshabadia ZS, Abdib E, Farahmanda F, et al (2016) A meshless method to simulate interactions between large soft tissue and a surgical grasper. Sci Iran Trans B, Mech Eng 23:295-300.

112. Dehghan MR, Rahimi A, Talebi HA, Zareinejad M (2016) A three-dimensional large deformation model for soft tissue using meshless method. Int J Med Robot Comput Assist Surg 12:241-253. doi: $10.1002 /$ rcs. 1682

113. Zou Y, Liu PX, Cheng Q, et al (2016) A New Deformation Model of Biological Tissue for Surgery Simulation. IEEE Trans Cybern 1-10. doi: 10.1109/TCYB.2016.2560938

114. Palyanov A, Khayrulin S, Larson SD (2016) Application of smoothed particle hydrodynamics to modeling mechanisms of biological tissue. Adv Eng Softw 98:1-11. doi: 10.1016/j.advengsoft.2016.03.002

115. Grabski JK, Lesnic D, Johansson BT (2016) Identification of a time-dependent bio-heat blood perfusion coefficient. Int Commun Heat Mass Transf 75:218-222. doi: 10.1016/j.icheatmasstransfer.2015.12.028

116. Pan J, Yan S, Qin H, Hao A (2016) Real-time dissection of organs via hybrid coupling of geometric metaballs and physics-centric mesh-free method. Vis Comput. doi: 10.1007/s00371-016-1317-x

117. Rausch MK, Karniadakis GE, Humphrey JD (2016) Modeling Soft Tissue Damage and Failure Using a Combined Particle / Continuum Approach. Biomech Model Mechanobiol. doi: 10.1007/s10237-0160814-1

118. Soleimani M, Wriggers P, Rath H, Stiesch M (2016) Numerical simulation and experimental validation of biofilm in a multi-physics framework using an SPH based method. Comput Mech 58:619-633. doi: $10.1007 / \mathrm{s} 00466-016-1308-9$

119. García JM, Doblaré M, Cueto E (2000) Simulation of bone internal remodeling by means of the $\alpha$ shape-based natural element method. In: European Congress on Computational Methods in Applied 
Sciences and Engineering (ECCOMAS 2000). Barcelona, pp 11-14

120. Wolff J (1892) Das Gesetz der Transformation der Knochen. Pro Business, Berlin

121. Doblaré M, García JM (2002) Anisotropic bone remodelling model based on a continuum damagerepair theory. J Biomech 35:1-17. doi: 10.1016/S0021-9290(01)00178-6

122. Fernandez JW, Das R, Thomas CDL, et al (2010) Strain reduction between cortical pore structures leads to bone weakening and fracture susceptibility: An investigation using smooth particle hydrodynamics. In: 6th World Congress of Biomechanics (WCB 2010). Springer Berlin Heidelberg, Singapore, pp 784787

123. Fernandez JW, Das R, Cleary PW, et al (2013) Using smooth particle hydrodynamics to investigate femoral cortical bone remodelling at the Haversian level. Int J Numer Method Biomed Eng 29:129-143. doi: 10.1002/cnm.2503

124. Doblaré M, Cueto E, Calvo B, et al (2005) On the employ of meshless methods in biomechanics. Comput Methods Appl Mech Eng 194:801-821. doi: 10.1016/j.cma.2004.06.031

125. Lee JD, Chen Y, Zeng X, et al (2007) Modeling and simulation of osteoporosis and fracture of trabecular bone by meshless method. Int J Eng Sci 45:329-338. doi: 10.1016/j.ijengsci.2007.03.007

126. Taddei F, Pani M, Zovatto L, et al (2008) A new meshless approach for subject-specific strain prediction in long bones: Evaluation of accuracy. Clin Biomech 23:1192-1199. doi: 10.1016/j.clinbiomech.2008.06.009

127. Deng Q, Chen Y, Lee JD (2009) An investigation of the microscopic mechanism of fracture and healing processes in cortical bone. Int J Damage Mech 18:491-502. doi: 10.1177/1056789508096563

128. Uscilowska A, Fraska A (2012) A mesh-free numerical method for the estimation of the torsional stiffness of long bones. J Mech Mater Struct 7:265-276. doi: 10.2140/jomms.2012.7.265

129. Dinis LMJS, Jorge RMN, Belinha J (2010) Bone remodelling optimization using the Natural Neighbour Radial Point Interpolation. In: Proceedings of the 2nd International Conference on Engineering Optimization. Lisbon, Portugal, pp 13-17

130. Belinha J, Jorge RMN, Dinis LMJS (2012) Bone tissue remodelling analysis considering a radial point interpolator meshless method. Eng Anal Bound Elem 36:1660-1670. doi: 10.1016/j.enganabound.2012.05.009

131. Belinha J, Jorge RMN, Dinis LMJS (2012) A meshless microscale bone tissue trabecular remodelling analysis considering a new anisotropic bone tissue material law. Comput Methods Biomech Biomed Engin 16:1-15. doi: 10.1080/10255842.2012.654783

132. Belinha J, Dinis L, Jorge RMN (2015) The osteointegration numerical prediction of a femur stem using a meshless approach. In: 2015 IEEE 4th Portuguese Meeting on Bioengineering (ENBENG). IEEE, Porto, Portugal, pp 1-6

133. Grivas KN, Vavva MG, Sellountos EJ, et al (2013) A meshless Local Boundary Integral Equation 
(LBIE) method for cell proliferation predictions in bone healing. Proc Annu Int Conf IEEE Eng Med Biol Soc EMBS 2676-2679. doi: 10.1109/EMBC.2013.6610091

134. Grivas KN, Vavva MG, Sellountos EJ, et al (2015) A meshless LBIE/LRBF method for solving the nonlinear Fisher equation: Application to bone healing. Comput Model Eng Sci 105:87-122. doi: $10.3970 /$ cmes.2015.105.087

135. Yang JP (2014) Image-Based Procedure for Biostructure Modeling. J Nanomechanics Micromechanics 4:B4013001. doi: 10.1061/(ASCE)NM.2153-5477.0000086

136. Yang JP, Chi SW, Chen JS (2013) Image-based multiscale modeling of porous bone materials. In: Li S, Qian D (eds) Multiscale simulations and mechanics of biological materials. John Wiley \& Sons Ltd, Oxford, pp 377-401

137. Harrison SM, Cleary PW (2014) Towards modelling of fluid flow and food breakage by the teeth in the oral cavity using smoothed particle hydrodynamics (SPH). Eur Food Res Technol 238:185-215. doi: 10.1007/s00217-013-2077-8

138. Cleary PW, Sinnott MD, Hari B, et al (2015) Modelling food digestion. Elsevier Ltd.

139. Cleary PW, Harrison S (2016) Modeling food digestion in the oral cavity. In: Reference Module in Food Science. Elsevier, pp 1-10

140. Harrison SM, Cleary PW, Eyres G, et al (2014) Challenges in computational modelling of food breakdown and flavour release. Food Funct 5:2792-2805. doi: 10.1039/C4FO00786G

141. Ho AK, Tsou L, Green S, Fels S (2014) A 3D swallowing simulation using smoothed particle hydrodynamics. Comput Methods Biomech Biomed Eng Imaging Vis 2:237-244. doi: $10.1080 / 21681163.2013 .862862$

142. Tse B, Barrow A, Quinn B, Harwin WS (2015) A smoothed particle hydrodynamics algorithm for haptic rendering of dental filling materials. In: 2015 IEEE World Haptics Conference (WHC). IEEE, pp $321-326$

143. Andrade J, Belinha J, Dinis L (2013) Analysis of dental implant using a meshless method. In: Jorge RMN, Campos JCR, Manuel J, et al (eds) Biodental Engineering II. CRC Press, London, pp 145-150

144. Belinha J, Dinis LMJS, Jorge RMN (2014) Mandible bone tissue remodelling analysis using a new numerical approach. In: Jorge RMN, Campos JCR, Manuel J, et al (eds) Biodental Engineering II. Taylor \& Francis Group, pp 151-157

145. Belinha J, Dinis LMJS, Jorge RMN (2014) The bone tissue remodelling analysis in dentistry using a meshless method. In: Jorge RMN, Campos JCR, Vaz MAP, et al (eds) Biodental Engineering III. Taylor \& Francis Group, London, pp 213-219

146. Belinha J, Dinis LMJS, Natal Jorge RM (2015) The mandible remodeling induced by dental implants: a meshless approach. J Mech Med Biol 15:1550059. doi: 10.1142/S0219519415500591

147. Carter DR, Fyhrie DP, Whalen RT (1987) Trabecular bone density and loading history: regulation of 
connective tissue biology by mechanical energy. J Biomech 20:785-794. doi: 10.1016/00219290(87)90058-3

148. Duarte HMS, Dinis LMJS, Jorge RMN (2014) Analysis of a bar-implant using a meshless method. In: Jorge RMN, Campos JCR, Manuel J, et al (eds) Biodental Engineering II. Taylor \& Francis Group, London, pp 139-144

149. Duarte HMS, Andrade JR, Dinis LMJS, et al (2015) Numerical analysis of dental implants using a new advanced discretization technique. Mech Adv Mater Struct 23:00-00. doi: $10.1080 / 15376494.2014 .987410$

150. Yamaguchi S, Coelho PG, Thompson VP, et al (2014) Dynamic finite element analysis and moving particle simulation of human enamel on a microscale. Comput Biol Med 55:53-60. doi: 10.1016/j.compbiomed.2014.10.005

151. Moreira SF, Belinha J, Dinis LMJS, Jorge RMN (2014) A global numerical analysis of the "central incisor / local maxillary bone" system using a meshless method. Mol Cell Biomech 11:151-184. doi: 10.3970/mcb.2014.011.151

152. Moreira SF, Belinha J, Dinis LMJS, Jorge RMN (2014) A meshless method analysis of maxillary central incisor. In: Jorge RMN, Campos JCR, Manuel J, et al (eds) Biodental Engineering II. Taylor \& Francis Group, London, pp 159-161

153. Tavares CSS, Belinha J, Dinis LMJS, Jorge RMN (2014) Numerical analysis of a teeth restoration: A meshless method approach. In: Jorge RMN, Campos JCR, Vaz MAP, et al (eds) Biodental Engineering III. Taylor \& Francis Group, London, pp 207-211

154. Tavares CSS, Belinha J, Dinis LMJS, Jorge RMN (2015) The numerical analysis of a restored tooth using meshless methods. In: 2015 IEEE 4th Portuguese Meeting on Bioengineering (ENBENG). IEEE, Porto, Portugal, pp 1-6

155. Belinha J, Dinis LMJS, Natal Jorge RM (2015) The analysis of the bone remodelling around femoral stems: A meshless approach. Math Comput Simul 121:64-94. doi: 10.1016/j.matcom.2015.09.002

156. Santos CF, Belinha J, Gentil F, et al (2018) The free vibrations analysis of the cupula in the inner ear using a natural neighbor meshless method. Eng Anal Bound Elem 92:50-63. doi: 10.1016/j.enganabound.2018.01.002

157. Hon YC, Lu MW, Xue WM, Zhou X (2002) Numerical algorithm for triphasic model of charged and hydrated soft tissues. Comput Mech 29:1-15. doi: 10.1007/s00466-002-0307-1

158. Marai GE, Crisco JJ, Laidlaw DH (2006) A kinematics-based method for generating cartilage maps and deformations in the multi-articulating wrist joint from CT images. Proc 28th IEEE EMBS Annu Int Conf 2079-2082. doi: 10.1109/IEMBS.2006.259742

159. Boyer P, Joslin C (2014) A smoothed particle hydrodynamics approach to simulation of articular cartilage. Am J Biomed Eng 4:41-52. doi: 10.5923/j.ajbe.20140402.03

160. Boyer P, Leblanc S, Joslin C (2015) Smoothed particle hydrodynamics applied to cartilage deformation. 
In: Cai Y, See S (eds) GPU Computing and Applications. Springer Singapore, Singapore, pp 151-165

161. Cyr A, Maletsky L (2014) Technical note: a multi-dimensional description of knee laxity using radial basis functions. Comput Methods Biomech Biomed Engin 18:1-6. doi: 10.1080/10255842.2014.946913

162. Chen J-S, Basava RR, Zhang Y, et al (2015) Pixel-based meshfree modelling of skeletal muscles. Comput Methods Biomech Biomed Eng Imaging Vis 4:1-13. doi: 10.1080/21681163.2015.1049712

163. Valizadeh N, Bazilevs Y, Chen J-SS, Rabczuk T (2015) A coupled IGA-Meshfree discretization of arbitrary order of accuracy and without global geometry parameterization. Comput Methods Appl Mech Eng 293:20-37. doi: 10.1016/j.cma.2015.04.002

164. Peña E, Martínez MA, Calvo B, Doblaré M (2008) Application of the natural element method to finite deformation inelastic problems in isotropic and fiber-reinforced biological soft tissues. Comput Methods Appl Mech Eng 197:1983-1996. doi: 10.1016/j.cma.2007.12.018

165. Doweidar MH, Calvo B, Alfaro I, et al (2010) A comparison of implicit and explicit natural element methods in large strains problems: Application to soft biological tissues modeling. Comput Methods Appl Mech Eng 199:1691-1700. doi: 10.1016/j.cma.2010.01.022

166. Boselli F, Kleiser L, Bockisch CJ, et al (2014) Quantitative analysis of benign paroxysmal positional vertigo fatigue under canalithiasis conditions. J Biomech 47:1853-1860. doi: 10.1016/j.jbiomech.2014.03.019

167. Boselli F, Obrist D, Kleiser L (2013) A meshless boundary method for Stokes flows with particles: Application to canalithiasis. Int J Numer Method Biomed Eng 29:1176-1191. doi: 10.1002/cnm.2564

168. Boselli F, Obrist D, Kleiser L (2012) A multilayer method of fundamental solutions for Stokes flow problems. J Comput Phys 231:6139-6158. doi: 10.1016/j.jcp.2012.05.023

169. Liu H, Shi P (2003) Meshfree representation and computation: Applications to cardiac motion analysis. In: Taylor CJ, Noble JA (eds) Information processing in medical imaging. Springer Berlin Heidelberg, Berlin, pp 560-572

170. Wang K, Liu H, Sinusas A, Shi P (2004) Multiframe nonrigid motion analysis with anisotropic spatial constraints: Applications to cardiac image analysis. In: IEEE International Conference on Image Processing, ICIP. IEEE, pp 131-134

171. Wong CL, Liu H, Wong LN, et al (2004) Meshfree cardiac motion analysis using composite material model and total Lagrangian formulation. In: 2nd IEEE International Symposium on Biomedical Imaging: Nano to Macro. IEEE, pp 464-467

172. Zhuang L, Liu H, Bao H, Shi P (2007) Volumetric meshfree framework for joint segmentation and motion tracking of the left ventricle. In: 4th IEEE International Symposium on Biomedical Imaging: From Nano to Macro. IEEE, Arlington, VA, pp 396-399

173. Wong KCL, Wang L, Zhang H, et al (2010) Meshfree implementation of individualized active cardiac dynamics. Comput Med Imaging Graph 34:91-103. doi: 10.1016/j.compmedimag.2009.05.002 
174. Wang Y, Rudy Y (2006) Meshless methods in potential inverse electrocardiography. In: IEEE Engineering in Medicine and Biology Annual International Conference. IEEE, New York, pp 25582559

175. Wang Y, Rudy Y (2006) Application of the method of fundamental solutions to potential-based inverse electrocardiography. Ann Biomed Eng 34:1272-1288. doi: 10.1007/s10439-006-9131-7

176. Li ZS, Zhu SA, He B (2007) Solving the ECG forward problem by means of a meshless finite element method. Phys Med Biol 52:N287-N296. doi: 10.1088/0031-9155/52/13/N02

177. Wang L, Wong KCL, Zhang H, Shi P (2009) Electrocardiographic simulation on coupled meshfree-bem platform. In: Ayache N, Delingette H, Sermesant M (eds) Functional Imaging and Modeling of the Heart. Springer Berlin Heidelberg, pp 162-171

178. Chen T, Wang X, Metaxas D, Axel L (2008) Fast motion tracking of tagged MRI using anglepreserving meshless registration. Lect Notes Artif Intell Lect Notes Bioinforma 313-320. doi: $10.1007 / 978-3-540-85990-1-38$

179. Ting Chen, Xiaoxu Wang, Metaxas D, Axel L (2008) 3D cardiac motion tracking using Robust Point Matching and meshless deformable models. In: 2008 5th IEEE International Symposium on Biomedical Imaging: From Nano to Macro. IEEE, pp 280-283

180. Wang X, Chen T, Zhang S, et al (2008) LV motion and strain computation from tMRI based on meshless deformable models. In: Metaxas D, Axel L, Fichtinger G, Székely G (eds) Medical Image Computing and Computer-Assisted Intervention - MICCAI 2008. Springer Berlin Heidelberg, pp 636644

181. Wang X, Chen T, Zhang S, et al (2015) Meshless deformable models for 3D cardiac motion and strain analysis from tagged MRI. Magn Reson Imaging 33:146-160. doi: 10.1016/j.mri.2014.08.007

182. Wang X, Mihalef V, Qian Z, et al (2012) 3D cardiac motion reconstruction from CT data and tagged MRI. Proc Annu Int Conf IEEE Eng Med Biol Soc EMBS 4083-4086. doi: 10.1109/EMBC.2012.6346864

183. Yu Y, Zhang S, Yan Z, et al (2013) Mouse LV 3D motion and strain analysis using tagged MRI. In: IEEE 10th International Symposium on Biomedical Imaging. IEEE, San Francisco, CA, pp 1190-1193

184. Bogatyrenko E, Hanebeck UD, Szabó G (2009) Heart surface motion estimation framework for robotic surgery employing meshless methods. 2009 IEEE/RSJ Int Conf Intell Robot Syst IROS 2009 67-74. doi: 10.1109/IROS.2009.5354398

185. Bogatyrenko E, Pompey P, Hanebeck UD (2011) Efficient physics-based tracking of heart surface motion for beating heart surgery robotic systems. Int J Comput Assist Radiol Surg 6:387-399. doi: $10.1007 / \mathrm{s} 11548-010-0517-5$

186. Chinchapatnam P, Rhode K, Ginks M, et al (2009) Voxel based adaptive meshless method for cardiac electrophysiology simulation. In: Ayache N, Delingette H, Sermesant M (eds) Functional Imaging and Modeling of the Heart. Springer Berlin Heidelberg, pp 182-190 
187. Pashaei A, Sebastian R, Zimmerman V, et al (2009) A mesh-less approach for fast estimation of electrical activation time in the ventricular wall. In: Computers in Cardiology, 2009. IEEE, Park City, UT, USA, pp 209-212

188. Zhang H, Ye H, Huang W (2012) A meshfree method for simulating myocardial electrical activity. Comput Math Methods Med 2012:. doi: 10.1155/2012/936243

189. Amanifard N, Rahbar B, Hesan M (2011) Numerical simulation of the mitral valve opening using smoothed particle hydrodynamics. In: Proceedings of the World Congress on Engineering. London, pp $2308-2312$

190. Yu Z, Yao G, Hoshijima M, et al (2011) Multiscale modeling of calcium dynamics in ventricular myocytes with realistic transverse tubules. IEEE Trans Biomed Eng 58:2947-2951. doi: 10.1109/TBME.2011.2158316

191. Yao G, Yu Z (2012) A localized meshless approach for modeling spatial-temporal calcium dynamics in ventricular myocytes. Int J Numer Method Biomed Eng 28:187-204. doi: 10.1002/cnm.1453

192. Shahriari S, Kadem L, Rogers BD, Hassan I (2012) Smoothed particle hydrodynamics method applied to pulsatile flow inside a rigid two-dimensional model of left heart cavity. Int J Numer Method Biomed Eng 28:1121-1143. doi: 10.1002/cnm.2482

193. Shahriari S, Maleki H, Hassan I, Kadem L (2012) Evaluation of shear stress accumulation on blood components in normal and dysfunctional bileaflet mechanical heart valves using smoothed particle hydrodynamics. J Biomech 45:2637-2644. doi: 10.1016/j.jbiomech.2012.08.009

194. Skatulla S, Legner D, Rama RR, et al (2013) Computational study of the injection therapy for myocardial infarction during the necrotic stage. In: Papadrakakis M, Kojic M, Tuncer I, Papadopoulos V (eds) Proceedings of 3rd South-East European Conference on Computational Mechanics. Kos Island, Greece, pp 12-14

195. Rama RR, Skatulla S, Sansour C (2015) Real-time modelling of the heart using the proper orthogonal decomposition with interpolation. In: VI International Conference on Computational Bioengineering ICCB 2015. Elsevier Ltd, Barcelona, Spain, pp 1-12

196. Rama RR, Skatulla S (2018) Towards real-time modelling of passive and active behaviour of the human heart using PODI-based model reduction. Comput Struct. doi: 10.1016/j.compstruc.2018.01.002

197. Rama RR, Skatulla S (2018) Towards real-time cardiac mechanics modelling with patient-specific heart anatomies. Comput Methods Appl Mech Eng 328:47-74. doi: 10.1016/j.cma.2017.08.015

198. Lluch È, Doste R, Giffard-Roisin S, et al (2017) Smoothed Particle Hydrodynamics for Electrophysiological Modeling: An Alternative to Finite Element Methods. In: Functional Imaging and Modelling of the Heart: 9th International Conference, FIMH 2017, Toronto, ON, Canada, June 11-13, 2017, Proceedings. pp 333-343

199. Sack KL, Skatulla S, Sansour C (2015) Biological tissue mechanics with fibres modelled as onedimensional Cosserat continua. Applications to cardiac tissue. Int J Solids Struct 81:84-94. doi: 
10.1016/j.ijsolstr.2015.11.009

200. Boselli F, Vermot J (2016) Live imaging and modeling for shear stress quantification in the embryonic zebrafish heart. Methods 94:129-134. doi: 10.1016/j.ymeth.2015.09.017

201. Mao W, Li K, Sun W (2016) Fluid-Structure Interaction Study of Transcatheter Aortic Valve Dynamics Using Smoothed Particle Hydrodynamics. Cardiovasc Eng Technol 7:374-388. doi: 10.1007/s13239016-0285-7

202. von Ellenrieder N, Muravchik CH, Nehorai A (2005) A meshless method for solving the EEG forward problem. IEEE Trans Biomed Eng 52:249-257. doi: 10.1109/TBME.2004.840499

203. von Ellenrieder N, Muravchik CHH, Nehorai A (2003) Effect of perturbations in the geometry on the electroencephalography inverse problem. IEEE Work Stat Signal Process 2003 2003-Janua:286-289. doi: 10.1109/SSP.2003.1289400

204. Peng L, Peng M, Xu A (2015) Effects of head models and dipole source parameters on EEG fields. Open Biomed Eng J 9:10-16. doi: 10.2174/1874120701509010010

205. Ala G, Di Blasi G, Francomano E (2012) A numerical meshless particle method in solving the magnetoencephalography forward problem. Int J Numer Model Electron Networks, Devices Fields 25:428-440. doi: 10.1002/jnm.1828

206. Ala G, Francomano E (2013) A multi-sphere particle numerical model for non-invasive investigations of neuronal human brain activity. Prog Electromagn Res Lett 36:143-153. doi: 10.2528/PIERL12110906

207. Ala G, Francomano E, Fasshauer GE, et al (2015) A Meshfree Solver for the MEG Forward Problem. IEEE Trans Magn 51:1-4. doi: 10.1109/TMAG.2014.2356134

208. Ala G, Fasshauer G, Francomano E, et al (2015) The method of fundamental solutions in solving coupled boundary value problems for M/EEG. SIAM J Sci Comput 37:570-590. doi: $10.1137 / 13094921 \mathrm{X}$

209. Ala G, Fasshauer GE, Francomano E, et al (2015) A novel numerical meshless approach for electric potential estimation in transcranial stimulation. In: Z. K, T.E. S, T. M, et al (eds) International Conference of Computational Methods in Sciences and Engineering 2015, ICCMSE 2015. AIP Publishing, Università degli Studi di Palermo, DEIM, Viale delle Scienze, Palermo, Italy, p 190025

210. Horton A, Wittek A, Miller K (2006) Towards meshless methods for surgical simulation. In: Miller K, Poulikakos D (eds) Computational Biomechanics for Medicine: MICCAI 2006 Workshop. Copenhagen, Denmark, pp 34-42

211. Horton A, Wittek A, Miller K (2007) Subject-specific biomechanical simulation of brain indentation using a meshless method. Med Image Comput Comput Assist Interv 10:541-8.

212. Horton A, Wittek A, Joldes GR, Miller K (2010) A meshless Total Lagrangian explicit dynamics algorithm for surgical simulation. Int $\mathrm{J}$ Numer Method Biomed Eng 26:977-998. doi: $10.1002 / \mathrm{cnm} .1374$ 
213. Miller K, Wittek A, Joldes G (2010) Biomechanics of the brain for computer-integrated surgery. Acta Bioeng Biomech 12:25-37.

214. Miller K, Joldes GR, Horton A, et al (2010) Modelling brain deformations for computer-integrated neurosurgery. Int J Numer Method Biomed Eng 26:117-138. doi: 10.1002/cnm.1260

215. Zhang GY, Wittek A, Joldes GR, et al (2014) A three-dimensional nonlinear meshfree algorithm for simulating mechanical responses of soft tissue. Eng Anal Bound Elem 42:60-66. doi: 10.1016/j.enganabound.2013.08.014

216. Berger J, Horton A, Joldes G, et al (2008) Coupling finite element and mesh-free methods for modelling brain defromations in response to tumour growth. In: Miller K, Nielsen PMF (eds) Computational Biomechanics for Medicine III : MICCAI 2008 Workshop. New York, pp 68-82

217. Chowdhury HA, Joldes GR, Wittek A, et al (2015) Implementation of a modified moving least squares approximation for predicting soft tissue deformation using a meshless method. In: Doyle B, Miller K, Wittek A, Nielsen PMF (eds) Computational Biomechanics for Medicine. Springer International Publishing, Switzerland, pp 59-71

218. Diaz I, Boulanger P (2015) Atlas to patient registration with brain tumor based on a mesh-free method. In: 2015 37th Annual International Conference of the IEEE Engineering in Medicine and Biology Society (EMBC). IEEE, pp 2924-2927

219. Marques M, Belinha J, Dinis LMJ, Natal Jorge R (2018) A brain impact stress analysis using advanced discretization meshless techniques. Proc Inst Mech Eng Part H J Eng Med 232:257-270. doi: $10.1177 / 0954411917751559$

220. Tang D, Yang C, Petruccelli JD, et al (2007) Quantifying human atherosclerotic plaque growth function using multi-year in vivo MRI and meshless local Petrov-Galerkin method. In: 2007 IEEE/ICME International Conference on Complex Medical Engineering, CME 2007. IEEE, Beijing, pp 546-551

221. Yang C, Tang D, Yuan C, et al (2008) Meshless generalized finite difference method and human carotid atherosclerotic plaque progression simulation using multi-year MRI patient-tracking data. Comput Model Eng Sci 28:95-107.

222. Yang C, Tang D, Atluri S (2010) Three-dimensional carotid plaque progression simulation using meshless generalized finite difference method based on multi-year MRI patient-tracking data. Comput Model Eng Sci 57:51-76. doi: 10.3970/cmes.2010.057.051

223. Yang C, Tang D, Atluri S (2011) Patient-specific carotid plaque progression simulation using 3D meshless generalized finite difference models with fluid-structure interactions based on serial in vivo MRI data. Comput Model Eng Sci 72:53-77. doi: 10.3970/cmes.2011.072.053

224. Tang D, Yang C, Kobayashi S, Ku DN (2001) Generalized finite difference method for 3-D viscous flow in stenotic tubes with large wall deformation and collapse. Appl Numer Math 38:49-68. doi: $10.1016 / \mathrm{S} 0168-9274(00) 00062-3$

225. Tang D, Yang C, Kobayashi S, et al (2003) Effect of stenosis asymmetry on blood flow and artery 
compression: A three-dimensional fluid-structure interaction model. Ann Biomed Eng 31:1182-1193. doi: $10.1114 / 1.1615577$

226. Tang D, Yang C, Kobayashi S, Ku DN (2001) Steady Flow and Wall Compression in Stenotic Arteries: A Three-Dimensional Thick-Wall Model With Fluid-Wall Interactions. J Biomech Eng 123:548. doi: $10.1115 / 1.1406036$

227. Belinha J, Dinis L, Jorge RN (2015) An elasto-plastic model to analyse the biomechanical behaviour of the atherosclerotic plaque tissue. In: 2015 IEEE 4th Portuguese Meeting on Bioengineering (ENBENG). IEEE, Porto, Portugal

228. Sinnott MD, Cleary PW, Harrison SM, et al (2015) How arterial pressures affect the consideration of internal carotid artery angle as a risk factor for carotid artherosclerotic disease. Prog Comput Fluid Dyn an Int J 15:87-101. doi: 10.1504/PCFD.2015.068817

229. El Zahab Z, Divo E, Kassab A (2009) A localized collocation meshless method (LCMM) for incompressible flows CFD modeling with applications to transient hemodynamics. Eng Anal Bound Elem 33:1045-1061. doi: 10.1016/j.enganabound.2009.03.006

230. El Zahab Z, Divo E, Kassab AA (2009) A meshless CFD approach for evolutionary shape optimization of bypass grafts anastomoses. Inverse Probl Sci Eng 17:411-435. doi: 10.1080/17415970902765434

231. El Zahab Z, Divo E, Kassab A (2010) Minimisation of the wall shear stress gradients in bypass grafts anastomoses using meshless CFD and genetic algorithms optimisation. Comput Methods Biomech Biomed Engin 13:35-47. doi: 10.1080/10255840903013555

232. Tanaka N, Takano T (2005) Microscopic-scale simulation of blood flow using SPH method. Int J Comput Methods 02:555-568. doi: 10.1142/S021987620500065X

233. Bao YD, Wu DM (2015) Virtual training system with physical viscoelastic model and blood flow simulation based on a range-based SPH method. J Biomimetics, Biomater Biomed Eng 25:41-53. doi: 10.4028/www.scientific.net/JBBBE.25.41

234. Wu J, Chui CK, Teo CL (2015) A software component approach for GPU accelerated physics-based blood flow simulation. In: 2015 IEEE International Conference on Systems, Man, and Cybernetics. IEEE, pp 2465-2470

235. Caballero A, Mao W, Liang L, et al (2017) Modeling Left Ventricular Blood Flow Using Smoothed Particle Hydrodynamics. Cardiovasc Eng Technol 8:465-479. doi: 10.1007/s13239-017-0324-z

236. Tsubota K, Wada S, Yamaguchi T (2006) Particle method for computer simulation of red blood cell motion in blood flow. Comput Methods Programs Biomed 83:139-46. doi: 10.1016/j.cmpb.2006.06.005

237. Chui Y-P, Heng P-A (2010) A meshless rheological model for blood-vessel interaction in endovascular simulation. Prog Biophys Mol Biol 103:252-61. doi: 10.1016/j.pbiomolbio.2010.09.003

238. Hosseini SM, Feng JJ (2012) How malaria parasites reduce the deformability of infected red blood cells. Biophys J 103:1-10. doi: 10.1016/j.bpj.2012.05.026 
239. Gholami B, Comerford A, Ellero M (2014) A multiscale SPH particle model of the near-wall dynamics of leukocytes in flow. Int J Numer Method Biomed Eng 30:83-102. doi: 10.1002/cnm.2591

240. Topalovic MD, Blagojevic MR, Nikolic A V., et al (2015) Application of smoothed particle hydrodynamics in biomechanics: Advanced procedure for discretization of complex biological shapes into pseudo-particles. In: 2015 IEEE 15th International Conference on Bioinformatics and Bioengineering (BIBE). IEEE, pp 1-4

241. Yamaguchi T, Ishikawa T, Imai Y, et al (2010) Particle-based methods for multiscale modeling of blood flow in the circulation and in devices: challenges and future directions. Ann Biomed Eng 38:1225-1235. doi: 10.1007/s10439-010-9904-x

242. Tosenberger A, Salnikov V, Bessonov N, et al (2011) Particle Dynamics Methods of Blood Flow Simulations. Math Model Nat Phenom 6:320-332. doi: 10.1051/mmnp/20116512

243. Moreno N, Vignal P, Li J, Calo VM (2013) Multiscale Modeling of Blood Flow: Coupling Finite Elements with Smoothed Dissipative Particle Dynamics. Procedia Comput Sci 18:2565-2574. doi: 10.1016/j.procs.2013.05.442

244. Bian X, Litvinov S, Qian R, et al (2012) Multiscale modeling of particle in suspension with smoothed dissipative particle dynamics. Phys Fluids 24:. doi: 10.1063/1.3676244

245. Li X, Popel AS, Karniadakis GE (2012) Blood-plasma separation in Y-shaped bifurcating microfluidic channels: a dissipative particle dynamics simulation study. Phys Biol 9:026010. doi: 10.1088/1478$3975 / 9 / 2 / 026010$

246. Pan W, Caswell B, Karniadakis GE (2010) A low-dimensional model for the red blood cell. Soft Matter 6:4366. doi: 10.1039/c0sm00183j

247. Quinn DJ, Pivkin I, Wong SY, et al (2011) Combined simulation and experimental study of large deformation of red blood cells in microfluidic systems. Ann Biomed Eng 39:1041-1050. doi: 10.1007/s10439-010-0232-y

248. Fedosov DA, Lei H, Caswell B, et al (2011) Multiscale modeling of red blood cell mechanics and blood flow in malaria. PLoS Comput Biol 7:. doi: 10.1371/journal.pcbi.1002270

249. Fedosov DA, Caswell B, Karniadakis GE (2010) Systematic coarse-graining of spectrin-level red blood cell models. Comput Methods Appl Mech Eng 199:1937-1948. doi: 10.1016/j.cma.2010.02.001

250. Pivkin I, Karniadakis G (2008) Accurate coarse-grained modeling of red blood cells. Phys Rev Lett 101:118105. doi: 10.1103/PhysRevLett.101.118105

251. Xiao LL, Chen S, Lin CS, Liu Y (2014) Simulation of a single red blood cell flowing through a microvessel stenosis using dissipative particle dynamics. Mol Cell Biomech 11:67-85. doi: 10.3970/mcb.2014.011.067

252. Yamada T, Kumar A, Asako Y, Faghri M (2010) Three dimensional simulation of dynamics and deformation of red blood cells in capillary flow. In: Proceedings of the ASME 2010 International Mechanical Engineering Congress \& Exposition (IMECE2010). ASME, British Columbia, Canada, pp 
$1-6$

253. Peng Z, Li X, Pivkin I V., et al (2013) Lipid bilayer and cytoskeletal interactions in a red blood cell. Proc Natl Acad Sci 110:13356-13361. doi: 10.1073/pnas.1311827110

254. Müller M, Schirm S, Teschner M (2004) Interactive blood simulation for virtual surgery based on smoothed particle hydrodynamics. Technol Health Care 12:25-31.

255. Liang CX, Zhang CY, Liu HY, et al (2012) Modeling low Reynolds number incompressible flows with curved boundaries using SPH. Int J Numer Methods Fluids 68:1173-1188. doi: 10.1002/fld.2600

256. Chui YP, Heng PA (2012) A particle-based modeling framework for thrombo-emboli simulation. In: Proceedings of the 11th ACM SIGGRAPH International Conference on Virtual-Reality Continuum and its Applications in Industry - VRCAI '12. ACM, Singapore, p 213

257. Kulp S, Gao M, Zhang S, et al (2013) Practical patient-specific cardiac blood flow simulations using SPH. In: 2013 IEEE 10th International Symposium on Biomedical Imaging. IEEE, pp 832-835

258. Maciel A, De S (2008) An efficient dynamic point algorithm for line-based collision detection in real time virtual environments involving haptics. Comput Animat Virtual Worlds 19:151-163. doi: $10.1002 /$ cav.224

259. Rahmanian E, Navidbakhsh M, Mohammadzadeh M, Habibi H (2015) Numerical simulation of blood flow in centrifugal heart pump by utilizing meshless smoothed particles hydrodynamic method. Int $\mathbf{J}$ Bio-Science Bio-Technology 7:73-82. doi: 10.14257/ijbsbt.2015.7.3.08

260. Li H, Ye T, Lam KY (2012) A novel interface-tracking method based on Lagrangian particles for deformation analysis of a red blood cell in a capillary. Int J Numer Methods Fluids 69:1031-1044. doi: 10.1002/fld.2624

261. Noguchi H (2010) Dynamical modes of deformed red blood cells and lipid vesicles in flows. Prog Theor Phys Suppl 184:364-368. doi: 10.1143/PTPS.184.364

262. Ahmadian MT, Firoozbakhsh K, Hasanian M (2011) Simulation of red blood cell motion in microvessels using modified moving particle semi-implicit method. Sci Iran 19:113-118. doi: 10.1016/j.scient.2011.12.007

263. Gambaruto AM (2015) Computational haemodynamics of small vessels using the Moving Particle Semi-implicit (MPS) method. J Comput Phys 302:68-96. doi: 10.1016/j.jcp.2015.08.039

264. Ariane M, Allouche MH, Bussone M, et al (2017) Discrete multi-physics: A mesh-free model of blood flow in flexible biological valve including solid aggregate formation. PLoS One 12:1-15. doi: 10.1371/journal.pone.0174795

265. Liu Y, Liu WK (2006) Rheology of red blood cell aggregation by computer simulation. J Comput Phys 220:139-154. doi: 10.1016/j.jcp.2006.05.010

266. Roohani Ghehsareh H, Karimi K, Zaghian A (2015) Numerical solutions of a mathematical model of blood flow in the deforming porous channel using radial basis function collocation method. J Brazilian 
Soc Mech Sci Eng 0-11. doi: 10.1007/s40430-015-0478-2

267. Van Liedekerke P, Ghysels P, Tijskens E, et al (2010) A particle-based model to simulate the micromechanics of single-plant parenchyma cells and aggregates. Phys Biol 7:026006. doi: $10.1088 / 1478-3975 / 7 / 2 / 026006$

268. Van Liedekerke P, Tijskens E, Ramon H, et al (2010) Particle-based model to simulate the micromechanics of biological cells. Phys Rev E 81:061906. doi: 10.1103/PhysRevE.81.061906

269. Karunasena HCP, Senadeera W, Brown RJ, Gu YT (2014) Simulation of plant cell shrinkage during drying - A SPH-DEM approach. Eng Anal Bound Elem 44:1-18. doi: 10.1016/j.enganabound.2014.04.004

270. Karunasena HCP, Senadeera W, Gu YT, Brown RJ (2014) A coupled SPH-DEM model for micro-scale structural deformations of plant cells during drying. Appl Math Model 38:3781-3801. doi: 10.1016/j.apm.2013.12.004

271. Perré P, Almeida G, Ayouz M, Frank X (2015) New modelling approaches to predict wood properties from its cellular structure: image-based representation and meshless methods. Ann For Sci 73:147-162. doi: 10.1007/s13595-015-0519-0

272. Nakamura M, Bessho S, Wada S (2014) Analysis of red blood cell deformation under fast shear flow for better estimation of hemolysis. Int J Numer Method Biomed Eng 30:42-54. doi: 10.1002/cnm.2587

273. Shankar V, Wright GB, Kirby RM, Fogelson AL (2015) Augmenting the immersed boundary method with Radial Basis Functions (RBFs) for the modeling of platelets in hemodynamic flows. Int J Numer Methods Fluids 79:536-557. doi: 10.1002/fld.4061

274. Xiang P, Liew KM (2011) Predicting buckling behavior of microtubules based on an atomisticcontinuum model. Int J Solids Struct 48:1730-1737. doi: 10.1016/j.ijsolstr.2011.02.022

275. Xiang P, Liew KM (2012) Free vibration analysis of microtubules based on an atomistic-continuum model. J Sound Vib 331:213-230. doi: 10.1016/j.jsv.2011.08.024

276. Xiang P, Liew KM (2013) A computational framework for transverse compression of microtubules based on a higher-order Cauchy-Born rule. Comput Methods Appl Mech Eng 254:14-30. doi: 10.1016/j.cma.2012.10.013

277. Xiang P, Liew KM (2012) Dynamic behaviors of long and curved microtubules based on an atomisticcontinuum model. Comput Methods Appl Mech Eng 223-224:123-132. doi: 10.1016/j.cma.2012.02.023

278. Liew KM, Xiang P, Zhang LW (2015) Mechanical properties and characteristics of microtubules: A review. Compos Struct 123:98-108. doi: 10.1016/j.compstruct.2014.12.020

279. Wang XY, Guo X, Su Z (2014) A quasi-continuum model for human erythrocyte membrane based on the higher order Cauchy-Born rule. Comput Methods Appl Mech Eng 268:284-298. doi: 10.1016/j.cma.2013.08.020 
280. Wang XY, Wang JB, Qiu BB, Hu LF (2015) Large deformation properties of red blood cell membrane based on a higher order gradient quasi-continuum model. J Membr Biol 1-12. doi: 10.1007/s00232-0159809-6

281. Zhang LW, Ademiloye AS, Liew KM (2017) A multiscale Cauchy-Born meshfree model for deformability of red blood cells parasitized by Plasmodium falciparum. J Mech Phys Solids 101:268284. doi: 10.1016/j.jmps.2017.01.009

282. Ademiloye AS, Zhang LW, Liew KM (2017) Element-free multiscale modeling of large deformation behavior of red blood cell membrane with malaria infection. In: Nithiarasu P, Robertson AM (eds) Proceedings of the 5th International Conference on Computational and Mathematical Biomedical Engineering (CMBE2017). Pittsburgh, USA, pp 316-319

283. Ademiloye AS, Zhang LW, Liew KM (2015) Numerical computation of the elastic and mechanical properties of red blood cell membrane using the higher-order Cauchy-Born rule. Appl Math Comput 268:334-353. doi: 10.1016/j.amc.2015.06.071

284. Ademiloye AS, Zhang LW, Liew KM (2018) A multiscale framework for large deformation modeling of RBC membranes. Comput Methods Appl Mech Eng 329:144-167. doi: 10.1016/j.cma.2017.10.004

285. Ademiloye AS, Zhang LW, Liew KM (2016) Predicting the elastic properties and deformability of red blood cell membrane using an atomistic-continuum approach. In: Feng DD, Korsunsky AM, Ao SI, et al (eds) Proceedings of the International MultiConference of Engineers and Computer Scientists 2016. Newswood Limited, Hong Kong, pp 942-946

286. Ademiloye AS, Zhang LW, Liew KM (2017) A three-dimensional quasicontinuum approach for predicting biomechanical properties of malaria-infected red blood cell membrane. Appl Math Model 49:35-47. doi: 10.1016/j.apm.2017.04.030

287. Ademiloye AS, Zhang LW, Liew KM (2016) Multiscale meshfree analysis of the effects of thermal treatments on deformability of red blood cell membrane. In: Bioinformatics and Bioengineering (BIBE), 2016 IEEE 16th International Conference on,. IEEE, Taichung, Taiwan, pp 186-191

288. Ademiloye AS, Zhang LW, Liew KM (2017) Atomistic-continuum model for probing the biomechanical properties of human erythrocyte membrane under extreme conditions. Comput Methods Appl Mech Eng 325:22-36. doi: 10.1016/j.cma.2017.06.033

289. Ademiloye AS, Liew KM, Zhang LW (2016) Numerical modeling of biomechanical responses of healthy red blood cell membrane under various loading conditions using a 3D quasicontinuum approach. In: 2016 International Conference on Biomedical Engineering (BME-HUST). IEEE, Hanoi, Vietnam, pp 119-124

290. Zeng X, Li S (2011) Multiscale modeling and simulation of soft adhesion and contact of stem cells. J Mech Behav Biomed Mater 4:180-189. doi: 10.1016/j.jmbbm.2010.06.002

291. Zeng X, Li S (2011) Modelling and simulation of substrate elasticity sensing in stem cells. Comput Methods Biomech Biomed Engin 14:447-458. doi: 10.1080/10255842.2011.557371 
292. Zeng X, Li S, Ren B (2012) Soft matter modeling of biological cells. In: Li S, Sun B (eds) Advances in Soft Matter Mechanics. Springer Berlin Heidelberg, pp 95-117

293. Singer SJ, Nicolson GL (1972) The fluid mosaic model of the structure of cell membranes. Science (80) 175:720-731. doi: 10.1126/science.175.4023.720

294. Helfrich W (1973) Elastic properties of lipid bilayers: theory and possible experiments. Z. Naturforsch. C. $28: 693-703$

295. Pothapragada S, Zhang P, Sheriff J, et al (2015) A phenomenological particle-based platelet model for simulating filopodia formation during early activation. Int J Numer Method Biomed Eng 31:. doi: 10.1002/cnm.2702

296. Heck T, Smeets B, Vanmaercke S, et al (2017) Modeling extracellular matrix viscoelasticity using noninertial smoothed particle hydrodynamics with improved boundary treatment. Comput Methods Appl Mech Eng 1-37. doi: 10.1016/j.cma.2017.04.031

297. Cohen RCZ, Cleary PW, Mason BR (2012) Simulations of dolphin kick swimming using smoothed particle hydrodynamics. Hum Mov Sci 31:604-619. doi: 10.1016/j.humov.2011.06.008

298. Cohen RCZ, Cleary PW, Mason B (2009) Simulation of human swimming using smoothed particle hydrodynamics. In: 7th International Conference on CFD in the Minerals and Process Industries. Melbourne, Australia, pp 1-6

299. Cohen RCZ, Cleary PW (2010) Computational studies of the locomotion of dolphins and sharks using smoothed particle hydrodynamics. In: Lim CT, Goh JCH (eds) IFMBE Proceedings. Springer Berlin Heidelberg, Berlin, Heidelberg, pp 22-25

300. Cohen RC. Z, Cleary PW, Harrison SM, et al (2014) Pitching effects of buoyancy during four competitive swimming strokes. J Appl Biomech 30:609-618. doi: 10.1123/JAB.2013-0260

301. Cohen RCZ, Cleary PW, Mason BR, Pease DL (2015) The Role of the Hand During Freestyle Swimming. J Biomech Eng 137:. doi: 10.1115/1.4031586

302. Harrison SM, Cohen RCZZ, Cleary PW, et al (2016) A coupled biomechanical-Smoothed Particle Hydrodynamics model for predicting the loading on the body during elite platform diving. Appl Math Model 40:3812-3831. doi: 10.1016/j.apm.2015.11.009

303. McCarthy MA, Xiao JR, McCarthy CT, et al (2004) Modelling of bird strike on an aircraft wing leading edge made from fibre metal laminates - Part 2: Modelling of impact with SPH bird model. Appl Compos Mater 11:317-340. doi: 10.1023/B:ACMA.0000037134.93410.c0

304. Guida M, Marulo F, Meo M, et al (2011) SPH - Lagrangian study of bird impact on leading edge wing. Compos Struct 93:1060-1071. doi: 10.1016/j.compstruct.2010.10.001

305. Grimaldi A, Sollo A, Guida M, Marulo F (2013) Parametric study of a SPH high velocity impact analysis - A birdstrike windshield application. Compos Struct 96:616-630. doi: 10.1016/j.compstruct.2012.09.037 
306. Hedayati R, Ziaei-Rad S (2013) A new bird model and the effect of bird geometry in impacts from various orientations. Aerosp Sci Technol 28:9-20. doi: 10.1016/j.ast.2012.09.002

307. Vignjevic R, Orłowski M, De Vuyst T, Campbell JC (2013) A parametric study of bird strike on engine blades. Int J Impact Eng 60:44-57. doi: 10.1016/j.ijimpeng.2013.04.003

308. Liu J, Li Y (2013) Numerical simulation of a rotary engine primary compressor impacted by bird. Chinese J Aeronaut 26:926-934. doi: 10.1016/j.cja.2013.06.006

309. Liu J, Li Y, Gao X, Yu X (2014) A numerical model for bird strike on sidewall structure of an aircraft nose. Chinese J Aeronaut 27:542-549. doi: 10.1016/j.cja.2014.04.019

310. Zhang D, Fei Q (2016) Effect of bird geometry and impact orientation in bird striking on a rotary jetengine fan analysis using SPH method. Aerosp Sci Technol 54:320-329. doi: 10.1016/j.ast.2016.05.003

311. Qian J, Lu J (2011) Point-cloud method for image-based biomechanical stress analysis. Int J Numer Method Biomed Eng 27:1493-1506. doi: 10.1002/cnm.1432

312. Zhou S, Zhang X, Ma H (2013) Numerical simulation of human head impact using the material point method. Int J Comput Methods 10:1350014. doi: 10.1142/S021987621350014X

313. Pekedis M, Yildiz H (2014) Numerical analysis of a projectile penetration into the human head via meshless method. J Mech Med Biol 14:1450059. doi: 10.1142/S0219519414500596

314. Prakash M, Cleary PW, Pyo SH, Woolard F (2015) A new approach to boiling simulation using a discrete particle based method. Comput Graph 53:118-126. doi: 10.1016/j.cag.2015.08.010

315. Huafeng Liu, Pengcheng Shi (2003) Meshfree particle method. In: Proceedings of the Ninth IEEE International Conference on Computer Vision. IEEE, pp 289-296

316. Chen T, Kim S, Zhou J, et al (2009) 3D meshless prostate segmentation and registration in image guided radiotherapy. In: Medical Image Computing and Computer-Assisted Intervention-MICCAI 2009. Springer Berlin Heidelberg, pp 43-50

317. Chen T, Kim S, Goyal S, et al (2010) Object-constrained meshless deformable algorithm for high speed 3D nonrigid registration between CT and CBCT. Med Phys 37:197-210. doi: 10.1118/1.3271389

318. Tao R, Tavakoli M, Sloboda R, Usmani N (2015) A comparison of US- versus MR-based 3-D prostate shapes using radial basis function interpolation and statistical shape models. IEEE J Biomed Heal Informatics 19:623-634. doi: 10.1109/JBHI.2014.2324975

319. Haq R, Aras R, Besachio DA, et al (2015) Minimally supervised segmentation and meshing of 3D intervertebral discs of the lumbar spine for discectomy simulation. In: Yao J, Glocker B, Klinder T, Li S (eds) Recent Advances in Computational Methods and Clinical Applications for Spine Imaging. Springer International Publishing, pp 143-155

320. Li M, Miller K, Joldes G, et al (2014) Patient-specific meshless model for whole-body image registration. In: Biomedical Simulation. Springer, pp 50-57

321. Li M, Miller K, Joldes GR, et al (2016) Biomechanical model for computing deformations for whole- 
body image registration: A meshless approach. Int J Numer Method Biomed Eng 32:. doi: $10.1002 / \mathrm{cnm} .2771$

322. An Y, Liu J, Zhang G, et al (2015) Meshless reconstruction method for fluorescence molecular tomography based on compactly supported radial basis function. J Biomed Opt 20:105003. doi: 10.1117/1.JBO.20.10.105003

323. Li S, Li X (2016) Radial basis functions and level set method for image segmentation using partial differential equation. Appl Math Comput 286:29-40. doi: 10.1016/j.amc.2016.04.002

324. Aggarwal A, Chen J-S, Klug WS (2014) A meshfree method for mechanics and conformational change of proteins and their assemblies. Comput Model Eng Sci 98:69-99. doi: 10.3970/cmes.2014.098.069

325. Siraj-ul-Islam, Ahmad I (2017) Local meshless method for PDEs arising from models of wound healing. Appl Math Model 48:688-710. doi: 10.1016/j.apm.2017.04.015

326. Cheng RJ, Zhang LW, Liew KM (2014) Modeling of biological population problems using the elementfree kp-Ritz method. Appl Math Comput 227:274-290. doi: 10.1016/j.amc.2013.11.033

327. Sinnott MD, Cleary PW, Arkwright JW, Dinning PG (2012) Investigating the relationships between peristaltic contraction and fluid transport in the human colon using Smoothed Particle Hydrodynamics. Comput Biol Med 42:492-503. doi: 10.1016/j.compbiomed.2012.01.002

328. Montanino A, Angelillo M, Pandolfi A (2018) Modelling with a meshfree approach the cornea-aqueous humor interaction during the air puff test. J Mech Behav Biomed Mater 77:205-216. doi: 10.1016/j.jmbbm.2017.05.042

329. Dehghan M, Mohammadi V (2017) Comparison between two meshless methods based on collocation technique for the numerical solution of four-species tumor growth model. Commun Nonlinear Sci Numer Simul 44:204-219. doi: 10.1016/j.cnsns.2016.07.024

330. Dehghan M, Narimani N (2018) An element-free Galerkin meshless method for simulating the behavior of cancer cell invasion of surrounding tissue. Appl Math Model 59:500-513. doi: 10.1016/j.apm.2018.01.034

331. Fu Z-J, Xi Q, Ling L, Cao C-Y (2017) Numerical investigation on the effect of tumor on the thermal behavior inside the skin tissue. Int $J$ Heat Mass Transf 108:1154-1163. doi: 10.1016/j.ijheatmasstransfer.2016.11.109

332. Jannesari Z, Tatari M (2017) A Meshfree Technique for Numerical Simulation of Reaction-Diffusion Systems in Developmental Biology. Adv Appl Math Mech 9:1225-1249. doi: 10.4208/aamm.2015.m1085

333. Ilati M, Dehghan M (2017) Application of direct meshless local Petrov-Galerkin (DMLPG) method for some Turing-type models. Eng Comput 33:107-124. doi: 10.1007/s00366-016-0458-x 


\section{Figure Legend}

Fig. 1 Illustration of the computational domain for a 2D skin model built on a rectangular area [93].

Fig. 2 Particles placed in the initial shape of the liver (left), and its magnified view (right). Particles of a fixed size are regularly placed in the liver. Light-gray-lined, black-lined and black-filled particles represent normal liver particles, metastasis particles and boundary particles, respectively [103].

Fig. 3 Geometry, boundary and loading conditions of a human proximal femur (left) and a meshless analysis model discretized with nodes (right) [34].

Fig. 4 Bone remodeling algorithm based on the NNRPIM meshless method (modified after [131]).

Fig. 5 Schematic diagram showing (a) a 2D model of a dental implant, (b) boundary and loading conditions, and (c) meshfree node distribution [143].

Fig. 6 Summarized implementation procedure of the MTLED algorithm (modified [212]). 